
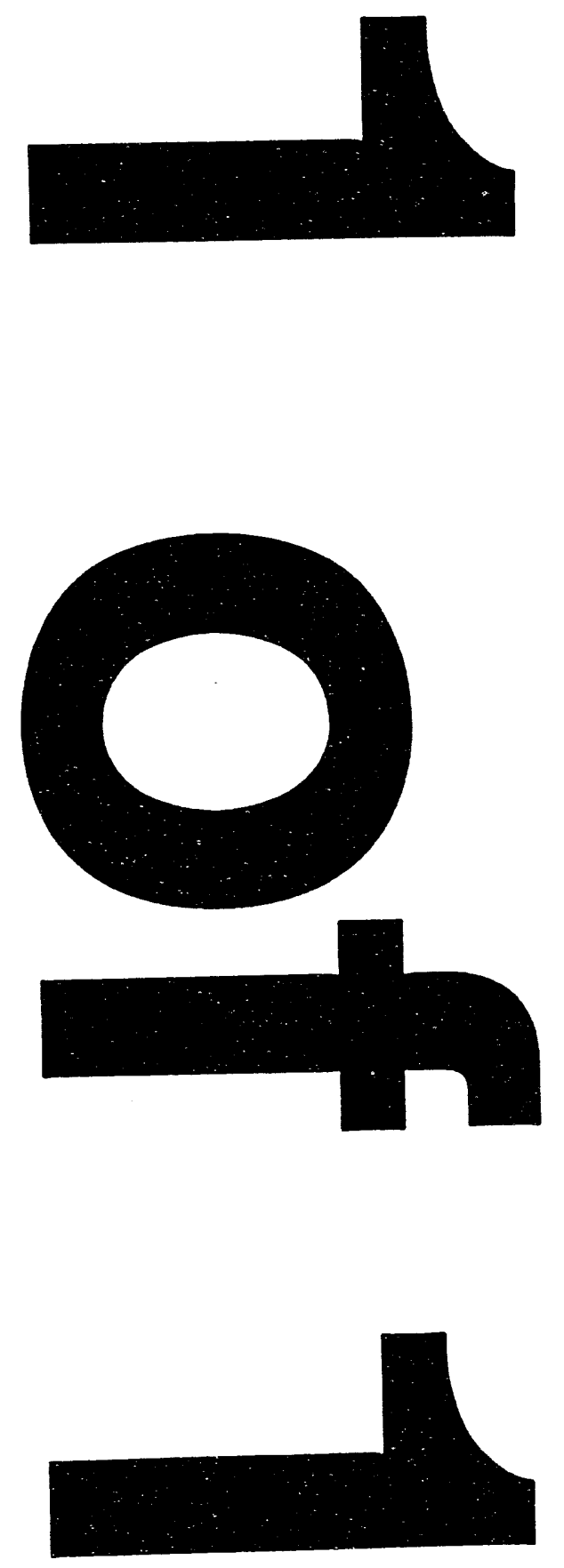


\section{RESPONSE TO THE INDEPENDENT TECHNICAL REVIEW of the UMTRA Project Procedures ANd Practices for Well Drilling AND DEVELOPMENT}

July 1994

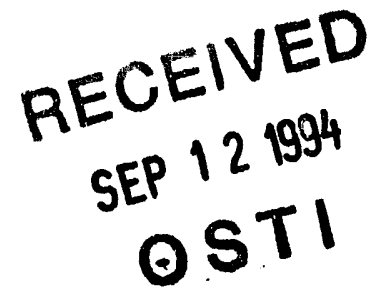

\section{DISCLAIMER}

This report was prepared as an account of work sponsored by an agency of the United States Neither the United States Government nor any agency thereof, nor any of their employees, makes any warranty, express or implied, or assumes any legal liability or responsibility for the accuracy, completeness, or usefulness of any information, apparatus, product, or process disclosed, or represents that its use would not infringe privately owned rights. Refer-

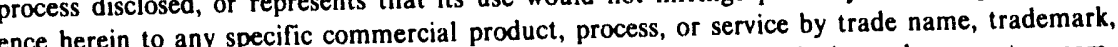
manufacturer, or otherwise does not necessarily constitute or imply its endorsement, recomme United States Government or any pgency thereof. The views mendation, or faverions of authors expressed herein do not necessarily state or reflect those of the United States Government or any agency thereof. 


\section{NOT INTENDED FOR PUBLIC RELEASE}

This report has been reproduced from the best available copy.

Number of pages in this report: 88

For availability contact:

Office of Scientific and Technical Information

P.O. Box 62

Oak Ridge, TN 37831

(615) 576-8401 


\section{RESPONSE TO THE INDEPENDENT TECHNICAL REVIEW OF THE UMTRA PROJECT PROCEDURES AND PRACTICES FOR WELL DRILLING AND DEVELOPMENT}

July 1994

Prepared for

U.S. Department of Energy UMTRA Project Office

Albuquerque, New Mexico

Prepared by Jacobs Engineering Group Inc.

Albuquerque, New Mexico 


\section{FOREWORD}

At the request of the Office of Independent Technical Review for the U.S. Department of Energy (DOE) Uranium Mill Tailings Remedial Action (UMTRA) Project, a Level I independent technical review (ITR) was conducted of the Technical Assistance Contractor's (TAC) well installation practices and procedures. The review was conducted August 3-5, 1993, in the Jacobs Engineering Group Inc. UMTRA Project Office in Albuquerque, New Mexico, by Robert D. Booth (SHB Agra, Inc., Albuquerque) and Fletcher G. Driscoll and Thomas L. Davis (Geraghty \& Miller, Inc., Minneapolis, Minnesota). The review coordinator was Michael S. Kearney (Roy F. Weston, Inc., Albuquerque).

The ITR review team represents many years of experience in the fields of well installation and development, client communications, and administrative issues directly related to successful environmental consulting projects. The purpose of their review was the application of their experience and expertise to the TAC's well installation and development procedures. Recognizing that successful drilling projects require more than technically correct standard operating procedures (SOP) (JEG, n.d.), the ITR team also examined and commented on drilling subcontracts, qualifications of TAC personnel assigned to oversee well installation, the organizational structure of the TAC, and lines of communication between the TAC and the DOE.

The ITR was conducted in accordance with the UMTRA Project Independent Technical Review Implementation Plan (DOE, 1992a). Copies of all material referenced during the ITR are contained in the UMTRA Project Document Control Center (TAC, 1993). A copy of the ITR report, Final Report of the UMTRA Project Independent Technical Review on Well Drilling and Development (DOE, 1993), is Appendix A to this document.

This report is a response to the findings and recommendations contained in the ITR report. The text of this document summarizes each ITR finding and recommendation, presents the TAC response, and concludes that implementation of many of the recommendations would benefit the UMTRA Project. Implementation of the recommendations represents ongoing improvement to the TAC well installation and development procedures and will result in lower overall project costs.

Appendix B is an implementation plan that groups similar or complementary action items, provides a schedule for implementation, identifies the group or people responsible for the changes, and estimates hours to implement the changes. The four major action items are as follows: 1) ITR Reevaluation, 2) Well Installation SOP Review and Revision, 3) Well Installation Contract Review and Revision, and 4) TAC and DOE Communications Improvement. The hours listed to implement the improvements are intended to be estimates for budgeting and planning purposes for the remainder of this fiscal year and the upcoming fiscal year. 


\section{TABLE OF CONTENTS}

Section

Page

FOREWORD

1. EMPLOYEE ATTITUDE REGARDING COOPERATION AND CHANGE $\ldots \ldots \ldots$

A. Initiative in Conducting Independent Technical Review . . . . . . . . . . . 1-1

B. Cooperative Attitude Among TAC Members . . . . . . . . . . . . . . 1-1

C. Future Needs Versus Current Needs . . . . . . . . . . . . . . . . 1-2

2. ORGANIZATIONAL STRUCTURE AND THE DECISION-MAKING PROCESS . . . 2-1

A. Existence of Operational Framework . . . . . . . . . . . . . 2-1

B. The Decision-Making Process Is Muddled at Two Levels in the

Organizational Framework .................... 2-1

C. DOE/TAC Roles on the Project Should Be Clarified ... . . . . . . . 2-2

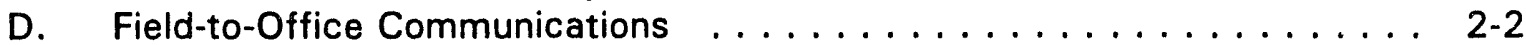

3. TECHNICAL STRATEGIES AND APPROPRIATE RISK ALLOCATION $\ldots \ldots \ldots$. . . 3-1

A. Flexible Proposed Action Strategies/Practical Approaches to Ground Water Restoration ........................ 3-1

B. Willingness of the TAC/DOE to Accept Risk to Begin Ground Water Restoration as Demonstrated by Selecting the Observational Method . . . 3-1

C. The Balance of Risk and Financial Liability Between the TAC and the Drilling Subcontractor .................... 3-1

4. UPGRADING QA/QUALITY CONTROL $\ldots \ldots \ldots \ldots \ldots \ldots \ldots \ldots \ldots \ldots$

A. Training Requirements for FTRs . . . . . . . . . . . . . . 4 4-1

B. Current Well Design and Construction Technologies Are Inconsistent with Future Demands Dictated by the Observational Method . . . . . . . . 4-1

C. Lack of Finished QAIP ....................... 4-2

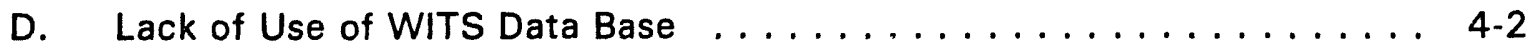

E. No Site Visit by Some Site Hydrogeologists . . . . . . . . . . . . . 4-3

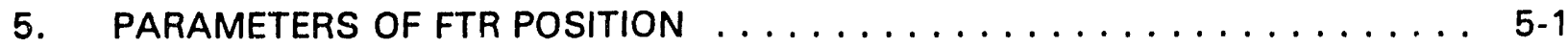

A. More Rigorous Assessment of FTR Skills Is Needed . . . . . . . . . . . 5-1

B. Lack of Decision-Making Ability of FTRs During Drilling . . . . . . . . 5-1

C. Lack of Guidance on the Flexibility Given to the FTR as to How Wells Are To Be Constructed Under the Constraints of the Contract . . . . . . 5 5-1

D. Ambiguity in Job Contract as to the Control that Can Be Exercised by the FTR .......................... 5-2

E. Lack of Formal Long-Term FTR Association with the Site . . . . . . . . 5-2

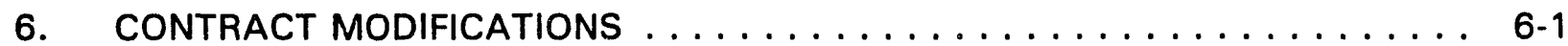

A. Contract Provisions ...................... 6-1 
TABLE OF CONTENTS (Concluded)

Section

Page

B. The 100 Percent Set Aside for Small Business May Restrict the Construction of High-Quality Wells ................... 6-1

7. LIST OF CONTRIBUTORS $\ldots \ldots \ldots \ldots \ldots \ldots \ldots \ldots \ldots$

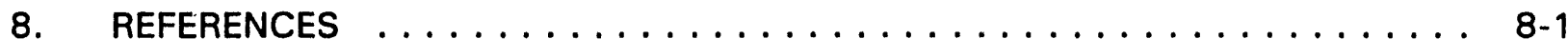

APPENDIX A FINAL REPORT OF THE UMTRA PROJECT INDEPENDENT TECHNICAL REVIEW ON WELL DRILLING AND DEVELOPMENT

APPENDIX B IMPLEMENTATION PLAN FOR ACTION ITEMS IDENTIFIED IN THE RESPONSE TO THE ITR ON WELL DRILLING AND DEVELOPMENT 


\section{LIST OF ACRONYMS AND ABBREVIATIONS}

\section{Acronym Definition}

CARD Characterization and Remedial Design

DOE U.S. Department of Energy

FTR field technical representative

H\&S Health and Safety Group

ITR independent technical review

QA quality assurance

QAIP quality assurance implementation plan

OC quality control

RFP request for proposal

SOP standard operating procedure

TAC Technical Assistance Contractor

TR technical representative

UMTRA Uranium Mill Tailings Remedial Action 


\section{EMPLOYEE ATTITUDE REGARDING COOPERATION AND CHANGE}

\section{A. Initiative in Conducting Independent Technical Review}

Findings: The Technical Assistance Contractor (TAC) is receptive to the peer review and independent technical review (ITR) processes. The review team commends the TAC's cooperative attitude, which will lead to improvement in the well drilling and development processes and productive review sessions.

Recommendations: The TAC should continue to expand the ITR process. Each review team should consist of four members (three technical experts and a team coordinator familiar with the project). The team should meet 9 to 12 months after this initial review to appraise the progress in implementing the changes suggested in the ITR report.

Response: The TAC will continue to have a cooperative and positive attitude towards the ITR process. An ITR reevaluation of well installation procedures will occur about 12 months after the ITR team receives this response document and revisions to the standard operating procedures (SOP) have been completed. (See the ITR reevaluation plan in Appendix B.)

\section{B. Cooperative Attitude Among TAC Members}

Findings: The TAC displayed a cooperative attitude toward the ITR team. This attitude was shown through generally favorable responses to the ITR process and candid discussions between the ITR team and TAC members; open discussions were possible that identified potential problems and solutions. The ITR team commends the TAC's cooperative attitude and recognizes that cooperation at all levels will foster improved practices. The cooperative attitude of members from all the TAC companies is a major reason for previous successes.

Recommendations: The TAC should establish teams to achieve a common goal of implementing the improvements suggested by the ITR and the TAC staff. A team facilitator should be appointed to direct productive meetings, to foster the idea that improving the well installation process is a team responsibility, and to encourage idea sharing between the team and TAC staff.

Response: A team of TAC members experienced in well installation and development will review and revise applicable SOPs. This team will consist of hydrogeologists and engineers from the Characterization and Remedial Design (CARD) Group, a member of the Health and Safety (H\&S) Group, and a member of the Quality Assurance (OA) Group. Issues involving contracting will be addressed by at least one representative of the Contracts, H\&S, QA, and CARD Groups. Because any changes will have the greatest effect on the CARD Group, the facilitator will be from the CARD Group and will be a member of both the SOP revision team and the contract revision team. (See the well installation SOP review and revision plan and the well installation contract review and revision plan in Appendix B.I 


\section{Future Needs Versus Current Needs}

Findings: Extensive changes are needed in the following areas:

- The technology level that guides the design and installation of monitor and extraction (remediation) wells.

- The ability of the technical representative (TR) and the field technical representative (FTR) to make out-of-scope (contract scope) changes in well construction and design, as needed in the field.

- The definition of lines of communication from the U.S. Department of Energy (DOE) and the TAC to the technical staff.

- The selection of appropriate methods and procedures.

- The development of rational field programs through a decision-making process.

Recommendations: The individuals affected by a proposed change should be fully informed of the change and charged with implementing the change under the guidance of an impartial facilitator.

Response: The TAC agrees with the findings and recommendations. A plan to address each finding and communicate the changes to the affected individuals is in Appendix $B$ (see the well installation SOP review and revision plan, the well installation contract review and revision plan, and the TAC and DOE communications improvement plan). 


\section{ORGANIZATIONAL STRUCTURE AND THE DECISION-MAKING PROCESS}

\section{A. Existence of Operational Framework}

Findings: The TAC has the framework of documented policies, procedures, and organizational structure needed to complete UMTRA Project work. However, certain documents contain insufficient guidance and some guidance is erroneous. For example, the quality assurance implementation plan (QAIP) (DOE, 1994) should be expanded and some of the SOPs should be updated. Additionally, the current organizational structure does not support rapid, effective decision making.

Recommendations: Suggested improvements to the guidance documents and the supporting operational framework are detailed in Section 4, Part B; Section 5, Parts C and D; and Section 6, Part B.

Response: The TAC agrees with the findings and has completed a revised QAIP. Improvements to the SOPs will be made; the specific operational changes and plan for revising the SOPs are in Appendix B (see the well installation SOP review and revision plan, the well installation contract review and revision plan, and the TAC and DOE communications improvement plan).

\section{B. The Decision-Making Process Is Muddled at Two Levels in the Organizational Framework}

Findings: Each engineer, hydrogeologist, and risk assessor has two line bosses at each site. Poor communication between individuals respe nsible for the various site activities results in a lack of coordination in reaching common site objectives, poor prioritization for site activities, and the potential for conflicting instructions with no one to act as arbiter. Commonly, differences in site-specific field objectives cannot be resolved.

Recommendations: A weekly meeting should be held for each site between the site manager, engineer, hydrogeologist, and risk assessor. The meeting should have an agenda established by the site manager or other appropriate person and should not be longer than 1 hour. A monthly meeting should also be held for each site, with the above personnel, Jim Gibb, Larry Pinkle, and other appropriate personnel. The meeting should have an agenda established by the site manager and should not be longer than 2 hours. The meeting schedule for each site should be evaluated after several months.

Response: The matrix management of the project requires multiple line bosses. The TAC acknowledges that one potential drawback of the matrix management system can result in the findings stated by the ITR. However, the TAC will continue to use the matrix system of management because of the many benefits.

Communication within the TAC will be improved through the implementation of, at a minimum, monthly meetings attended by the site manager, engineer, hydrogeologist, and risk assessor. The meetings will follow an agenda distributed at least one day before the meeting and one person will be designated to take notes. That individual will record discussions and decisions and prepare and 
distribute a memo to all who attended the meeting. As recommended, the meeting schedule will be evaluated after several months. (See the TAC and DOE communications improvement plan in Appendix B.I

\section{DOE/TAC Roles on the Project Should Be Clarified}

Findings: The overall direction of the UMTRA Project is not communicated to the staff. There is confusion about which entity (DOE or TAC) is responsible for providing technical direction to the staff. At present, a site hydrologist may be directed by several individuals from the DOE and TAC, resulting in conflicting assignments and unclear priorities. The Matrix Management System currently in use will not work if DOE continues to direct technical work at the technical support level.

Recommendations: Communication (of tasks and technical discussions) between the DOE and TAC should begin at the management level. Work should then be assigned to the technical staff only through TAC management.

Response: The TAC believes that although the present system fosters some confusion regarding technical direction to the staff, the system does promote open communication and exchange of ideas between the DOE and all members of the TAC. Therefore, TAC does not agree with the recommendation, but acknowledges that improvements are needed.

Training presented at two or more mandatory TAC staff meetings held by Jim Gibb or Roger Nelson will inform all members of the TAC staff that only managers can commit TAC resources. The periodic site-specific meetings discussed in the response to item $B$ should also assist in the proper delegation of resources and setting priorities. Another series of meetings (or at a minimurn, memos) between the TAC staff and the DOE to scope potential work, to review and approve work plans, and to review completed work will also improve communications. These meetings will be attended by all affected staff and their supervisors. (See the TAC and DOE communications improvement plan in Appendix B.)

\section{Field-to-Office Communications}

Findings: The SOPs adequately define instructions for communication between FTRs and TRs. However, the many site locations may make phone communication difficult. Also, the distance to a phone from remote sites may require lengthy drill rig shutdowns, resulting in high standby and project completion costs.

Recommendations: Assess the feasibility of cellular phone use and incorporate cellular phone communication into the SOPs.

Response: The use of cellular phones will be incorporated into the SOPs by the group assigned to modify the well installation SOPs. Cellular phones are already used successfully by the water sampling crews. (See the TAC and DOE communications improvement plan in Appendix B.) 


\section{TECHNICAL STRATEGIES AND APPROPRIATE RISK ALLOCATION}

\section{A. Flexible Propased Action Strategies/Practical Approaches to Ground Water Restoration}

Findings: Pump-and-treat methods of ground water restoration originally were proposed at all Uranium Mill Tailings Remedial Action (UMTRA) Project sites. Based on the results of an assessment of health risks associated with the contaminated water, the number of pump-and-treat sites was decreased to two (Tuba City and Monument Valley). The ITR agrees that ground water cleanup strategies should be selected on a site-specific basis using a health risk assessment.

Recommendations: Ground water restoration efforts should be prioritized by the degree of health risk posed by each site.

Response: Health evaluations will continue to be a factor in determining cleanup strategies.

\section{B. Willingness of the TAC/DOE to Accept Risk to Begin Ground Water Restoration as Demonstrated by Selecting the Observational Method}

Findings: The most cost-effective approach for ground water cleanup is the observational work plan approach, adopted by the TAC and DOE.

Recommendations: The ITR team agrees with the observational work plan approach and recommends mandatory training, using specific case histories.

Response: The ITR team findings are acknowledged and implementation of the observational work plan approach will continue. The recommendation for training will be adopted and implemented through in-house seminars (for the TAC and DOE) presented by members of the TAC and DOE. The first phase of the training will incorporate examples of successful applications of the approach to other government projects. Because observational work plans will be written in stages and only a few will be initiated each year, the second phase of the training will include presentations of the approach applied to UMTRA Project sites. (See the TAC and DOE communications improvement plan in Appendix B.)

\section{The Balance of Risk and Financial Liability Between the TAC and the Drilling Subcontractor}

Findings: The current request for proposal (RFP) for drilling and monitor well installation unfairly places financial liability on the drilling subcontractor. This is a result of the contract, which gives the FTR little authority to alter the terms of the contract, even when field conditions dictate otherwise. Only the contract representative may change, amend, or alter contract terms, which could lead to costly delays.

Recommendations: The TAC should assume greater risk during drilling operations when needed to ensure that all objectives for the well are attained. Other individuals (e.g., the 
TR and FTR) should be given the authority to alter contract conditions. The well installation subcontract and attachments to the RFPs should be thoroughly reviewed and all unnecessary documents should be removed. Adequately trained, more-experienced FTRs that can make field modifications to the contract would ensure that wells meet more of the primary objectives, reducing the overall financial risk to the project.

Response: The technical aspects of the contracts and RFPs will be thoroughly reviewed and modified to the extent possible. However, government contracting requirements impose some limitatiol s to RFP and contract modifications. The group appointed to review and revise SOPs (see the response to item 1.B) will be responsible for implementing the recommendation and training staff to inform them of changes to the procedures. (See the well installation contract review and revision plan in Appendix B.I 


\section{UPGRADING QA/QUALITY CONTROL}

\section{A. Training Requirements for FTRs}

Findings: The SOPs provide guidance for well installation. However, some of it is limited, erroneous, or contradictory. All pertinent SOPs were not analyzed.

All FTRs are interviewed to assess their experience and capabilities. The results of the interviews are not recorded. After the FTR is certified, follow-up interviews are not performed. Interviews are conducted by only one individual (Gerald Lindsey), with no indication that input from other team members is allowed.

Recommendations: Develop a more formal and documented process for the assessment and training of FTRs and clarify FTR field responsibilities.

Response: The TAC agrees with the findings and recommendations. Revisions to the SOPs will be implemented by the review group identified in item 1.B and will include modifications to the well installation procedures and a more formal and documented FTR assessment and preparation process. The FTR assessment and preparation process will be conducted by the SOP revision group and will include briefing sessions for the technical and health and safety aspects of each job. The briefing sessions will be held before and after each field activity.

The revised SOP will require more-experienced FTRs and will recommend the use of experienced site hydrologists as FTRs. The shift to site hydrologists will provide a higher degree of responsibility for well installation and will provide each site hydrologist greater site-specific knowledge. (See the well installation SOP review and revision plan in Appendix B.)

\section{B. Current Well Design and Construction Technologies Are Inconsistent with Futura Demarids Dictated by the Observational Method}

Findings: Some past well failures can be attributed to inappropriate design and construction standards. The observational approach requires hydraulically efficient wells, minimum well diameters of 4 inches, and a long life-span. The current well installation contract is inadequate because contract stipulations are unrealistic and impractical and because several viable drilling procedures and tools are prohibited. Using some well completion materials, such as prepacked well screens, has led to well failures. Well installation procedures that result in poor well construction include those for drilling methods, fluids, well construction materials, and grouting procedures required by the contract. (Examples of poor construction practices are cited in the ITR report [see Appendix A], including eliminating cement pads around completed wells, sealing the well annulus improperly, and considering a sediment-filled well screen a successful well installation.)

Recommendations: Use the best methods available in current technology. Use better well screens and casings (the cost of a continuous-slotted screen is minimal when compared with the overall well installation cost). The minimum well diameter must be 4 inches. 
FTRs must be sufficiently trained and experienced. Make note of previous errors and failures and modify procedures accordingly.

Response: The technical and contract revisions teams identified in item 1.B will address the SOPs and well installation contracts to achieve the goal of improved well design. This will include modifying well installation procedures, including grain-size analyses to size the sand pack and weli screens, eliminating the use of 2 -inch wells and prepacked well screens, using continuous-slotted well screens, and using proper grouting and well development techniques. Additionally, the site observational work plan will include evaluation of existing wells and improperly constructed wells will be abandoned. (See the well installation SOP review and revision plan and the contracts review and revisions plan in Appendix B.)

\section{Lack of Finished QAIP}

Findings: The QAIP is in draft form and does not give sufficient guidance for the ground water program. There is a misunderstanding regarding information that should be in the QAIP and the SOPs (e.g., aquifer tests are in the SOPs; water-level measurements are better described in the QAIP). The SOPs and QAIP are inconsistent (i.e., the reader is referred to a section of the SOP for information regarding aquifer and slug testing but that section contains no guidance on how to calibrate measuring devices).

Recommendations: Completing the QAIP should be high priority. The QAIP should establish project data-quality objectives. It should contain guidelines for assessing the adequacy of and adherence to SOPs. SOPs should contain basic quality assurance/quality control (QA/OC) guidance.

Response: The QAIP was finalized during the spring of 1994 and follows the outline described in the Guidance for Conducting Remedial Investigations and Feasibility Studies Under CERCLA (EPA, 1988). The QAIP contains the 14 sections described in the CERCLA guidance document, and four additional sections that cover personnel training and qualifications, documents and records, design, and procurement.

The QAIP clearly covers both the surface and ground water programs and the QAIP contains guidance for assessing the adequacy of and adherence to SOPs. An evaluation of the consistency between the QAIP and SOPs will be performed by a team consisting of the technical group identified in item 1.B and the QA Group. The newly completed QAIP and revised SOPs will be presented to the appropriate TAC personnel in a series of in-house training seminars presented by the QAIP/SOP review team. (See the well installation SOP review and revision plan in Appendix B.)

\section{Lack of Use of WITS Data Base}

Findings: The WITS data base is separate from SPEAR (DOE, 1992b) and contains substantially different but very important information critical to the future ground water program. The TAC uses the WITS data base infrequently, possibly because the data base 
is separate from SPEAR. Combining the two data bases may increase the use of information contained in WITS.

Recommendations: Evaluate the feasibility and costs of merging the SPEAR and WITS data bases as soon as possible. If merging is too costly, leave the data bases separate but educate the TAC about the capabilities of WITS.

Response: Combining the two data bases is being evaluated by the project computer management group and input has been provided from the technical staff regarding recommended changes and enhancements to the data bases. The possibility of transferring data to a commercially available program that has the additional capacity to include geologic logs, hydraulic properties, and cross-section information will also be explored. The feasibility of adding additional capabilities to SPEAR (e.g., plotting chemical concentrations compared to water levels) is also being evaluated by the technical and computer management groups. (See the TAC and DOE communications improvement plan in Appendix B.)

\section{E. No Site Visit by Some Site Hydrogeologists}

Findings: The QAIP contains guidance on the need for early site visits by the site hydrologists. However, some site hydrologists have not visited their sites. Other sites have been visited only after substantial work has been completed. Site visits are a very important aspect of site geologic and hydrologic interpretations and the costs of site visits are minimal when compared with successful project completion. Reviewing photographs and maps is not an acceptable substitute for site visits. The observational approach and successful cleanup strategies require site visits by the site hydrologist.

Recommendations: Site hydrologists must visit the site early. The site visits are not optional. The importance of the site visits must be clearly stated in the QAIP.

Response: The TAC agrees with the recommendations and has modified the QAIP to identify the importance of early and subsequent site visits. TAC senior management will educate the DOE regarding the cost-effectiveness of site visits as an important part of the approval process. The site hydrologist, or any member of the TAC requesting a site visit, could precede each trip with a written set of hypotheses to explore during the site visit, and there would be written follow-up to each visit that details the findings. This may encourage the DOE to approve more site visits. Additionally, using site hydrologists as FTRs during well installation will increase the number of site visits. (See the TAC and DOE communications improvement plan in Appendix B.) 



\section{PARAMETERS OF FTR POSITION}

(NOTE: Because the items discussed by the ITR in this section are similar, the TAC response is presented at the end of this section.)

\section{A. More Rigorous Assessment of FTR Skills Is Needed}

Findings: The assessment of FTR skills is informal and undocumented. Only one person interviews and decides which FTR is sent to perform fieldwork. No follow-up interviews are conducted when work is completed. FTRs can be sent out with a minimum of 3 days' training for well drilling operations. Follow-up training is not conducted. Current FTR evaluation procedures are inadequate and limit the direction that FTRs can give.

Recommendations: Better long- and short-term assessment of FTR skills is needed. Formalize the evaluation process and send the evaluations to the site manager, site hydrologist, and contract representative. Require more than 3 days of training. Upgrade SOPs to include regular, documented skill evaluations. Require the TR to visit the site during well installation to evaluate the FTR's abilities. Additionally, require the site manager and site hydrologist to evaluate the FTR's skills when the job is complete. Train some site hydrologists to act as the FTR.

\section{B. Lack of Decision-Making Ability of FTRs During Drilling}

Findings: Based on the Albuquerque Operations Manual and the current drilling and well installation contract, only the contract representative can redirect drilling efforts or change a contract. This limits the FTR's ability to change well specifications and leads to many failed well installations.

Recommendations: Expanding the role of the FTR in controlling well drilling operations requires more-experienced FTRs and modifications to the operations manual. Also needed are better communications between office and field, improved drilling contracts to include more drilling techniques, and an increased level of responsibility for the FTR in directing the well installation process.

\section{Lack of Guidance on the Flexibility Given to the FTR as to How Wells Are To Be Constructed Under the Constraints of the Contract}

Findings: Normally, the role of an FTR as a drilling superintendent requires that person to provide input during well installation. However, selecting an FTR only after the contract has been established prevents any technical input from the FTR. The role of the FTR is then limited to enforcing the terms of the contract, rather than ensuring proper well installation, even when field conditions dictate changes are needed.

Additionally, well construction techniques are constrained by wording in the contract, and operation manual instructions to the FTR are ambiguous and sometimes contradictory regarding the FTR's authority over the contractor's work. 
Recommendations: The FTR should have greater opportunity to control driller operations and modify terms of the contract, with the goal of installing a well that meets the objectives of the project. Contradictory wording in the operations manual regarding the FTR control over drilling operations should be clarified. The FTR should be instructed that modifications to drilling procedures may be required to ensure successful well installation.

\section{Ambiguity in Job Contract as to the Control that Can Be Exercised by the FTR}

Findings: The driller is responsible for mechanical operation of the drill rig. However, the FTR is responsible for control of the drilling operation. Control of the drilling operations by an experienced FTR will result in successful well completions. Because of their knowledge of site conditions and project requirements, the site hydrologists will be ideal FTRs.

Recommendations: Highly experienced FTRs will be more likely to gain the respect of, and will communicate more effectively with, the contractor. The FTR must be involved with more aspects of the job, including well design and project continuity. Improved communication between the FTR and contractor is very important to successful control of the drilling operations.

\section{E. Lack of Formal Long-Term FTR Association with the Site}

Findings: FTRs seldom have a long-term involvement with a particular site. The role of the FTR is to direct the drilling contractor and to report site technical and operational conditions accurately and consistently to the TAC. Therefore, information provided by the FTR must be consistent.

Recommendations: All attempts should be made to use the same FTR on a particular site.

Response to ITR Findings and Recommendations in section 5: Although the TAC agrees with the findings and recommendations, changes to the drilling contracts may be limited by government contracting procedures. However, the contracts will be reviewed and changed where possible. Additionally, the operations manual will be modified, communications between the field and contract representative will be improved through the use of cellular phones, more experienced FTRs will be used, and using site hydrologists as FTRs will be pursued. Modifications to the SOPs and contracts will be performed by the groups identified in the response to item 1.B and the action plan in Appendix $B$ (see the well installation SOP review and revision plan, the contracts review and revisions plan, and the TAC and DOE communications improvement plan). More-experienced FTRs will be obtained through a more rigorous interview program. The use of the site hydrologist as the FTR will address many of the concerns presented in the recommendations and findings. 


\section{CONTRACT MODIFICATIONS}

(NOTE: Because the items discussed by the ITR in this section are similar, the TAC response is presented at the end of this section.)

\section{A. Contract Provisions}

Findings: The contract documents and RFPs are too long and complex. The typical RFP sent to a potential contractor is more than 90 pages. Additional firms might respond to the RFPs if the contracts and scopes of work were revised. Additional responses could result in increased competition and could save the project money.

Recommendation: Shorten the RFP.

\section{B. The 100 Percent Set Aside for Small Business May Restrict the Construction of High-Quality Wells}

Findings: Future well construction contracts will require larger, more sophisticated equipment and the jobs will be more complex overall. Small business contractors may not be capable of performing the work and the set-aside will further reduce competition, resulting in higher costs.

Recommendations: Modify the requirements to include better drilling techniques and more sophisticated drilling equipment when necessary. Open the bidding to large companies.

Response to ITR Findings and Recommendations in section 6: The TAC agrees with the findings and recommendations and will modify the contracting requirements to the extent possible, within government contracting limitations. The modifications will be performed by the technical and contracts groups identified in the response to item 1.B. (See the well installation SOP review and revision plan and the contracts review and revisions plan in Appendix B.) 


\section{LIST OF CONTRIBUTORS}

The following individuals contributed to the preparation of this document.

\begin{tabular}{ll}
\hline Name & Contribution \\
\hline A. Miller & Primary author \\
J. Torline & Document production coordination \\
WordCenter, Inc. & Text processing \\
WordCenter, Inc. & Technical editing \\
\hline
\end{tabular}




\section{REFERENCES}

DCE (U.S. Department of Energy), 1994. Quality Assurance Implementation Plan, DOE/AL/62350-72, prepared by the U.S. Department of Energy, UMTRA Project Office, Albuquerque Operations Office, Albuquerque, New Mexico.

DOE (U.S. Department of Energy), 1993. Final Report on the UMTRA Project Independent Technical Review on Well Drilling and Development, UMiRA Project Office, Albuquerque Operations Office, Albuquerque, New Mexico.

DOE (U.S. Department of Energy), 1992a. UMTRA Project Independent Technical Review Implementation Plan, prepared by the U.S. Department of Energy, UMTRA Project Office, Albuquerque Operations Office, Albuquerque, New Mexicn.

DOE (U.S. Department of Energy), 1992b. Software Program for Environmental Analysis and Reporting (SPEAR) System, U.S. Department of Energy, UMTRA Project Office, Albuquerque Operations Office, Albuquerque, New Mexico.

EPA (U.S. Environmental Protection Agency), 1988. Guidance for Conducting Remedial Investigations and Feasibility Studies under CERCLA, interim final, EPA/540/ G-89/004, OSWER Directive 9355.3-01, Office of Emergency Response, Washington, DC.

JEG (Jacobs Engineering Group Inc.), n.d. Albuquerque Operations Manual, standard operating procedures, prepared by Jacobs Engineering Group Inc., Albuquerque, New Mexico, for the U.S. Department of Energy, UMTRA Project Office, Albuquerque Operations Office, Albuquerque, New Mexico.

TAC (Technical Assistance Contractor), 1993. "Ground Water Hydrology Designs and Reports," UPDCC File No. 0.19.2.8., UMTRA Project Office, Albuquerque Operations Office, Albuquerque, New Mexico. 
APPENDIX A

FINAL REPORT OF THE

UMTRA PROJECT INDEPENDENT TECHNICAL REVIEW

ON

WELL DRILLING AND DEVELOPMENT 
Find Report

of the

UMIrA Project Independent Technical Review

on

Well Drilling and Development

Technical Reviewers:

Robert D. Booth

$\frac{10-5 \cdot 93}{\text { Date }}$

SH\&B Agra, Inc.

Albuquerque, New Mexico

Alüans Dresan

Fletcher G. Driscoll

$9 / 23 / 93$

Geraghty \& Miller, Inc.

Minnespolis, Minnesota

Date

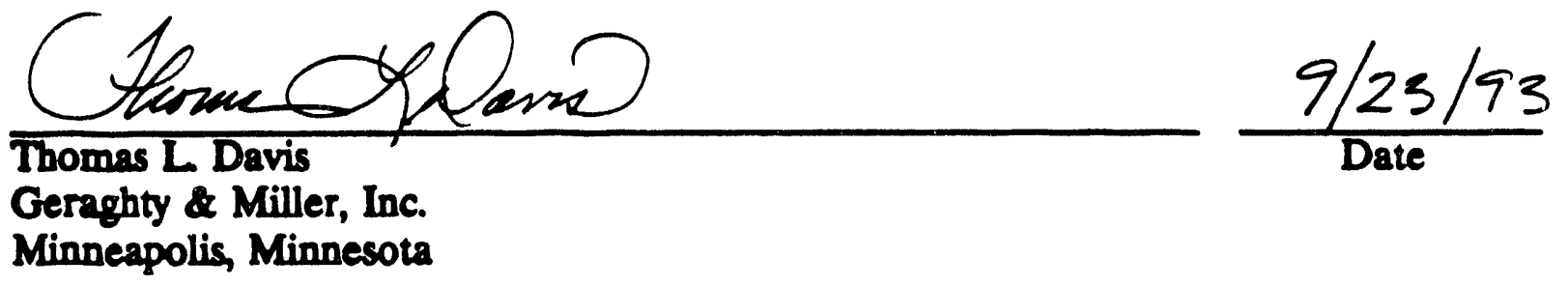




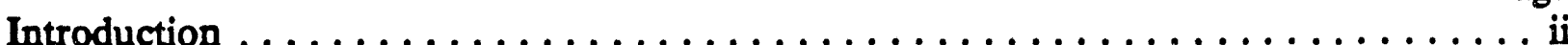

1. EMPLOYEE ATTTTUDE REGARDING COOPERATION AND CHANGE

A. Initiative in Conducting Independent Technical Review $\ldots \ldots \ldots \ldots \ldots 1$

B. Cooperative Attitude Among TAC Members $\ldots \ldots \ldots \ldots \ldots \ldots \ldots 1$

C. Future Needs Versus Current Needs $\ldots \ldots \ldots \ldots \ldots \ldots \ldots \ldots \ldots, 2$

2. ORGANIZATIONAL STRUCTURE AND THE DECISION-MAKING PROCESS

A. Existence of Operational Framework .................. 3

B. The Decision-Making Process is Muddled at Two Levels in the Organizational Framework ............................ 4

C. DOE/TAC Roles on the Project Should be Clarified .............. 5

D. Field-to-Office Communications $\ldots \ldots \ldots \ldots \ldots \ldots \ldots \ldots \ldots, 6$

3. TECHNICAL STRATEGIES AND APPROPRIATE RISK ALLOCATION

A. Flexible Proposed Action Strategies/Practical Approaches to Groundwater

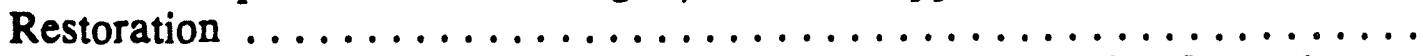

B. Willingness of the TAC/DOE to Accept Risk to Begin Groundwater Restoration as Demonstrated by Selecting the Observational Method ...... 7

C. Balance of Risk and Financial Liability Between the TAC and the Drilling Subcontractor $\ldots \ldots \ldots \ldots \ldots \ldots \ldots \ldots \ldots \ldots \ldots \ldots \ldots$

4. UPGRADING QA/QC

A. Training Requirements for FTRs ................... 9

B. Current Well Design and Construction Technologies are Inconsistent with Future Demands Dictated by the Observational Method ........... 10

C. Lack of Finished QAIP $\ldots \ldots \ldots \ldots \ldots \ldots \ldots \ldots \ldots \ldots \ldots, 13$

D. Lack of Use of WITS Database $\ldots \ldots \ldots \ldots \ldots \ldots \ldots \ldots \ldots, 14$

E. No Site Visit by Some Site Hydrogeologists $\ldots \ldots \ldots \ldots \ldots \ldots \ldots \ldots$

5. PARAMETERS OF FTR POSITION

A. More Rigorous Assessment of FTR Skills is Needed $\ldots \ldots \ldots \ldots \ldots \ldots 15$

B. Lack of Decision-Making Ability of FTRs During Drilling ......... 17

C. Lack of Guidance on the Flexibility Given to the FTR as to How Wells are to be Constructed Under the Constraints of the Contract ............ 19

D. Ambiguity in Job Contract as to the Control that Can be Exercised by the FTR ................................ 20

E. Lack of Formal Long-Term FTR Association with the Site ......... 21

6. CONTRACT MODIFICATIONS

A. Contract Provisions ......................... 22

B. The 100-Percent Set Aside for Small Business May Restrict the Construction

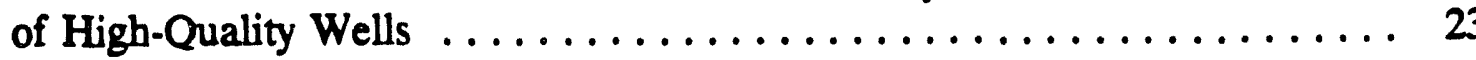

Attachment A: MK-Ferguson Geotechnical Drilling RFP dated July 15, 1993 


\section{Introduction}

This is the report of an Independent Technical Review (ITR) of the UMTRA (Uranium Mill Tailings Remedial Action) Technical Assistance Contractor's (TAC's) well installation practices and procedures. The review was conducted in the Jacobs Engineering Group's UMTRA Project Office in Albuquerque, New Mexico, from August 3rd to 5th, 1993. The technical reviewers were Robert D. Booth (SHB Agra, Inc., Albuquerque, NM), and Fletcher G. Driscoll and Thomas L Davis (Geraghty \& Miller, Minneapolis, MN). The review coordinator was Michael S. Kearney (Roy F. Westnn, Inc., Albuquerque, NM).

This Level I ITR was conducted in accordance with the UMTRA Project Independent Technical Review Implementation Plan: a copy of all material referred to in the performance of this review, including a copy of this report, has been placed in the TAC Project file 0.19.2.8, Groundwater Hydrology Designs and Reports.

Scope of Work: This ITR was commissioned to examine the TAC's well installation practices and procedures including the review of the appropriate SOP's, drilling subcontracts, and qualifications of TAC personnel assigned to oversee the installation of wells. Specific questions which the review group was to address are:

a. Should the UMTRA Project continue to use $2^{n}$ Schedule 40 PVC for monitor well installation? Should the well diameter and materials be varied for different deptbs? How should the construction techniques be modified for different depths?

The conclusion of the ITR Team is that most if not all future monitoring wells should be at least 4" in diameter. See Section 4, Part B.

b. Do the TAC's statements of work represent a reasonable balance of risk and financial liability between the subcontractor and the TAC?

In the ITR Team's view the standard contract appears to strike an unsatisfactory balance of risk and financial liability between the TAC and the drilling subcontractor. See Section 3, Part C.

c. Are the TAC well screen designs and associated packings adequate and representative of the current state of the art?

The ITR Team recommends that changes in well technology and drilling techniques be undertaken; the TR, SH, and FTR need to acquire additional information and experience on a much broader range of well technologies. See Section 4, Part B.

d. Are several recent well installation "failures" representative of a systemic problem?

The report makes recommendations in several areas that will help avoid reoccurrences of past well installation problems. See Sections 4, 5, and 6. 


\section{EMPIOYEE ATTITUDE REGARDING COOPERATION AND CHANGE}

\section{A. Initiative in Conducting Independent Technical Review}

The Independent Technical Review (ITR) 'Team salutes the UMTRA Technical Assistance Contractor (TAC) for initiating the peer review process for the UMTRA project. Exposing individual and group efforts to the sometimes harsh light of scrutiny by peers can be threatening. But, by setting aside self-inierest and placing short-perm personal comfort at risk, the TAC members have shown the great courage necessary to achieve team success and foster improvement of processes that will enhance the UMTRA project.

The technical and operational insights offered by the ITR Team are the primary result of the ITR process sought by the TAC. Yet, the non-threatening dialogue that was begun by the TAC and further established during the ITR process may be just as important as the technical improvements that will result from the ITR, and can provide the basis on which further progress can be made. This cooperative and non-threatening dialogue forms the foundation on which further positive action can be started during future independent reviews and project team interactions. We believe true improvement will come if those instrumental to effecting change continue to build on this cooperative spirit and thoughtfully consider and implement the suggestions submitted by the ITR Team.

\section{Recommendations}

The TAC should continue and expand the ITR process. Other areas of concern should be addressed by similarly constructed review teams. A four-member review team - three experts and a team coordinator familiar with the project - appears to work best to maintain the focus of the review and effectively resolve differences among team members.

To further enhance the process, each review team should reassemble nine to twelve months after the initial review to appraise the success of implementing changes suggested in its report. This session would serve to increase the effectiveness of the review and allow the ITR Team to give further guidance to the TAC staff if problems arose during implementation. The facc-to-face interview probably could be accomplished in two days at the TAC headquarters, followed up immediately by a report of findings and recommendations.

\section{B. Cooperative Attitude Among TAC Members}

It was refreshing to observe the cooperative attitude displayed by those interviewed during the ITR process. Nearly everyone responded favorably to the scrutiny under which they were placed by the ITR. Most spoke candidly with both the ITR and each other about 
problems they had encountered and remained open-minded to suggestions made by others. This attitude seems to be a major reason for the previous success of the TAC in spite of the administrative obstacles presented when people from several companies and different loyalties must work together. The cooperative attitude demonstrated by the TAC staff should be commended and further encouraged by project management staff.

Future cooperation among the key TAC decision-makers will determine how successful the TAC will be in realizing the benefits that result from the implementation of the ITR recommendations. In addition to cooperating with one another, these key decision-makers will need to include in the implementation process the project staff most affected by the changes suggested by the ITR. Strong and insightful leaders will be required to ensure that cooperation continues throughout this process.

\section{Recommendations}

The TAC should further promote the prevailing spirit of cooperation by establishing teams with the common goal of implementing improvements suggested by the ITR and TAC staff. These teams should be lead by a strong facilitator who will (1) insist on the continuation of non-threatening dialogue, (2) foster the notion that the team is ultimately responsible for improving the process in its care, and (3) encourage the sharing of ideas and the accompanying reasoning rather than allow others to defend carefully-guarded positions. In this way, the TAC will be most successful in bringing about desired changes.

\section{Future Needs Versus Current Needs}

Presentations by Jim Gibb, Linda Ulland, Gerald Lindsay, and others suggested that there is widespread recognition that future technical and administrative requirements for successful implementation of the UMTRA program will be both different and more rigorous than past or current practices. This evolution in overall planning and operational complexity is expected in a project of this magnitude. Recognition of enhanced demands, however, is only the first small step in achieving success.

Areas in which vital changes are needed include the following:

- Significantly enhancing the level of technology guiding the design and installation of both monitoring and extraction (remediation) wells.

- Augmenting the ability of the Technical Representative (TR) and the Field Technical Representative (FTR) to make well construction (or even design) changes in the field, even though these changes are out of scope vis-a-vis the contract.

- More clearly defining lines of communication from the Department of Energy (DOE) and TAC to the technical staff that would eliminate dual lines of reporting for the technical staff. 
- Recognizing that DOE is responsible for strategies, whereas the TAC is responsible for implementing these strategies by selection and use of appropriate technical methods and procedures.

- Creating a decision-making process that leads to the development of field programs that are rationally thought out.

It is clear that important changes need to be made in both technical areas as well as adrinistrative procedures. Because every individual working on the project has become "invested" in some or even all of the current methodologies, ill-defined or capricious changes in the system will create ill will that can reduce the hoped-for efficiencies created by the change. Thus, any changes, no matter how worthy they may be, must be orchestrated artfully to achieve maximum effectiveness. Changes brought about with full disclosure and participation of those affected are usually more effective.

\section{Recommendations}

Specific suggestions for changes are given throughout this report. Full understanding of the need for these changes must be established at every level of the project. To create this understanding and acceptance of the necessity for change, those individuals affected by a specific proposed change should be charged with working out appropriate ways to implement the change under the guidance of an impartial facilitator. It is the job of the facilitator to create a positive atmosphere while at the same time arriving at definite, acceptable conclusions on how to create the change. Insightful selection of the appropriate facilitator will be a key element in successful implementation of needed changes.

\section{ORGANIZATIONAL STRUCTURE AND THE DECISION-MAKING PROCESS}

\section{A. Existence of Operational Framework}

It is clear that as the UMTRA project has progressed the TAC has tried to build a framework within which it can work effectively. This framework includes the documented policies and procedures and the organizational structure necessary to completing UMTRA project work. For the most part, this operational framework now appears to be well established. Most procedures and processes fundamental to the progress of this part of the project appear to be described so that those who must carry out technical duties beyond the most routine tasks have some guidance. Whether the framework is adequate for all purposes cannot be determined within the limited scope of the current ITR. Certain documents contain insufficient guidance and some guidance is in error. For example, the Quality Assurance Implementation Plan (QAIP) needs to be expanded to include a more detailed discussion of elements of $Q A / Q C$ other than chemical analysis. Also, some of the standard operating procedures (SOPs) include guidance that will prove to be insufficient to ensure the success of the Groundwater program. Additionally, the current organizational structure does not support effective and rapid decision-making. 
Recommendations

Suggested improvements to the guidance documentation and the supporting operational framework are detailed in Section 4, Part B, Section 5, Parts C and D, and Section 6, Part B of this report.

\section{B. The Decision-Making Process is Muddled at Two Levels in the Organizational Framework}

A brief example of a portion of the Matrix Management organization is presented below.

\begin{tabular}{|c|c|c|c|c|}
\hline & & \multicolumn{3}{|c|}{ Jim Gibb } \\
\hline \multirow{4}{*}{$\begin{array}{l}\text { Larry } \\
\text { Pinkle }\end{array}$} & TM & $\begin{array}{c}\text { Task } \\
\text { Manager } \\
1\end{array}$ & $\begin{array}{c}\text { Task } \\
\text { Manager } \\
2\end{array}$ & $\begin{array}{c}\text { Task } \\
\text { Manager } \\
3\end{array}$ \\
\hline & $\begin{array}{c}\text { Site } \\
\text { Manager } \\
1\end{array}$ & $\begin{array}{c}\text { Engineer } \\
1\end{array}$ & $\begin{array}{c}\text { Hydrogeologist } \\
1\end{array}$ & $\begin{array}{c}\text { Risk } \\
\text { Assessor/ } \\
\text { RAD } \\
1 \\
\end{array}$ \\
\hline & $\begin{array}{c}\text { Site } \\
\text { Manager } \\
2\end{array}$ & $\begin{array}{c}\text { Engineer } \\
\quad 2\end{array}$ & $\begin{array}{c}\text { Hydrogeologist } \\
2\end{array}$ & $\begin{array}{c}\text { Risk } \\
\text { Assessor/ } \\
\text { RAD } \\
2\end{array}$ \\
\hline & $\begin{array}{c}\text { Site } \\
\text { Manager } \\
\mathbf{3}\end{array}$ & $\begin{array}{c}\text { Engineer } \\
3\end{array}$ & $\begin{array}{c}\text { Hydrogeologist } \\
3\end{array}$ & $\begin{array}{c}\text { Risk } \\
\text { Assessor/ } \\
\text { RAD } \\
3\end{array}$ \\
\hline
\end{tabular}

Under this organization each Engineer, Hydrogeologist, and Risk Assessor has two line bosses for a given site - the Site Manager (SM) and the Task Manager (TM). The TMs answer directly to Jim Gibb, while the SMs answer to Larry Pinkle. During the meeting at the UMTRA projects offices, it became apparent that there was a lack of communication between the various individuals assigned to a particular site. Mr. Gibb made a comment that the way he finds out there is a problem with a particular site is hearing people arguing in the halls. There were also comments that a Risk Assessor may be planning for wells to be constructed at a given site without the knowledge of the hydrogeologist or engineer.

Problems are cited at two levels within the organization - TM-SM and staff-technical levels. At the TM-SM level, there appears to be little coordination in reaching common objectives for a site before directives are given to technical/engineering staff. Thus, a technical staff 
member may receive contrary advice with no one to arbitrate the confusion. Similarly, at the staff level, various individuals often attempt to piggyback their projects onto someone else's. As a result, the principal objectives become muddled or unattainable in trying to meet the ancillary demands that have much less priority. Differences of opinion on field objectives cannot be arbitrated under the current system.

It is concluded that communication between all individuals working on a given site needs improvement for the Matrix Management system to work efficiently. It is our understanding that at least seven individuals are assigned to and are responsible for a given site. These individuals must communicate with each other on a regular basis.

\section{Recommendations}

It is recommended that weekly meetings be scheduled for each site to be attended by the SM, Engineer, Site Hydrogeologist (SH), and Risk Assessor. An agenda should be established for each meeting, and the meeting should last no more than one hour. In addition to the weekly meetings, monthly meetings should be scheduled for each site. These meetings should be attended not only by the site team members, but also by Jim Gibb, Larry Pinkle, and each TM. Others may be required to attend depending upon the agenda and items to be discussed. Again, an agenda should be established for each monthly meeting, and unless there are some major issues to be discussed or resolved, the meetings should last no longer than two hours. After several months, an evaluation should be made as to the value of the meetings and the meeting schedule be adjusted accordingly.

\section{DOE/TAC Roles on the Project Should be Clarified}

The ITR Team believes that the project's overall direction is not being adequately communicated to the staff. The staff has a lack of understanding as to which entity (the DOE or the TAC) is responsible for providing technical direction to the staff. At present, a site hydrologist is asked to perform a number of tasks by several individuals, both within the DOE and the TAC. These multiple task assignments are often accompanied by conflicting directions to the staff, and without a clear priority system for resolving conflicting work assignments.

It is concluded that the Matrix Management System currently being used by the TAC will not work if DOE personnel continue to direct the technical work at the technical staff level. With the Matrix Management System, a Site Hydrogeologist, Engineer, or Risk Assessor has two line bosses - the SM and the Technical Manager. Having a third line boss further complicates the system and leads to unnecessary additional confusion.

\section{Recommendations}

Although it is recognized that there is a friendly relationship between the DOE and the TAC and not an adversarial one, it is recommended that communication of work tasks (and resulting strategies) and technical discussions between the DOE and the TAC take place at 
the management level. Once unanimity has been reached, work assignments and technical directions should be given to the technical staff only from the management level of the TAC.

\section{Field-to-Omice Communications}

Instructions to the FTR regarding communication with the $T R$ are contained in the Albuquerque Operations Manual. In general, there is ample guidance to the FTR on when she or he must communicate with the TR. Communication standards are established for daily updates as well as for the instances in which the FTR must make immediate contact with the TR (Section 14.1.2, Part 4.3.1). The FTR must also contact the TR in all stop-work situations (Part 4.4.2).

Although the level of guidance given in the Operations Manual on communication may seem sufficient, practical application of communication standards may be difficult to achieve at many UMTRA sites. The remoteness of some sites, for example, makes it difficult for the FTR to reach a telephone without driving miles. In this instance, the use of a cellular phone would help reduce the time required to make the call. In addition, if the FTR needed to call the TR to confer on a drilling problem that could cause a temporary rig shutdown, the length of standby time would be minimized, if not altogether eliminated. Thus, the use of a cellular phone where possible would increase the level of contact between the TR and FTRs and also reduce operating costs. Furthermore, it would allow the TR to contact the FTR at will or to respond to an earlier FTR call that occurred when the TR was away from the phone.

Enhanced communication via cellular phones has another powerful advantage in that the FTR can easily seek assistance as needed from the SM, SH, and others. These contacts will help increase the chance for a successful drilling operation by "coaching" the FTR at the appropriate times. These contacts and their frequency may become more important if the suggestions given in Section 4, Part B and Section 5, Parts C and D of this report to increase the operational role of the FTR are adopted. Real time collaboration during the drilling and well installation process among the SM, SH, Contract Representative (CR), and others and the TR and FTRs will become even more important in the future as the size and cost of the wells increase.

Recommendation

The feasibility of using cellular telephones in support of the TAC's field work at each of the sites on the UMTRA Project should be assessed, and where feasible incorporated into the TAC's standard operating procedures. 


\section{TECHNICAL STRATEGIES AND APPROPRIATE RISK ALLOCATION}
A. Flexible Proposed Action Strategies/Practical Approaches to Groundwater Restoration

Pump-and-treat methods of groundwater restoration were originally being proposed at all of the UMTRA project sites. Since preliminary costs estimates for performing this method of groundwater restoration at all of the sites were high, it was decided to assess each of the sites in terms of health risk.

Contingent upon the results of future health risk assessments, the number of sites where pump-and-treat methods of groundwater restoration are currently being considered are two (Tuba City and Monument Valley). The Technical Review Committee agrees that selection of a groundwater restoration strategy should be determined on a site-by-site basis, and that the method chosen should based upon a health risk assessment.

\section{Recommendation}

It is recommended that groundwater restoration efforts be prioritized in terms of the degree of health risk involved at the various sites.

\section{B. Willingness of the TAC/DOE to Accept Risk to Begin Groundwater Restoration as Demonstrated by Selecting the Observational Method}

The observational method of groundwater restoration consists of implementing a remediation program based upon all currently available information concerning the geology and aquifer characteristics of a particular site. A simplified model of site characteristics based on available information is used to design the remediation system and predict expected performance of the system. The predicted response to the restoration program is then compared to observed responses and the remediation plan is modified as necessary based upon the response.

It is clear that there is enhanced risk in using the observational approach for the DOE/TACs. In some projects, an initial remedial design may fail completely - an event unlikely to happen if a thorough analysis of the hydrogeology has been made. In most cases, however, the initial remedial design adopted in the observational method will have varying degrees of success that can swiftly be improved upon by using actual data. Further-more, the remedy can be initiated much earlier.

The observational method has been used for many years in the field of geotechnical engineering for solving subsurface problems, and has proven to be a cost-effective solution to geotechnical engineering problems. Time constraints often make characterization of a site's geology and groundwater difficult to achieve with sufficient accuracy to design a "defect-free" remediation program. Thus, foregoing the costs of additional study, 
implementing a restoration program, and modifying that program as necessary based upon observed responses is considered the most cost-effective solution.

Recommendation

The ITR Team agrees that the observational method is an appropriate method for groundwater restoration. Training using specific case histories should be mandatory for project personnel.

\section{The Balance of Risk and Financial Lability Between the TAC and the Drilling Subcontractor}

Upon detailed review of the Request for Proposal for Drilling and Monitor Well Installation at the Shiprock, New Mexico Processing Site (RFP No. 05-62350-R-93-0008), there appears to be an unsatisfactory balance of risk and financial liability between the TAC and the drilling subcontractor. Currently the balance of risk is unfairly placed on the driller because the FTR has little authority to alter terms of the contract, even when field conditions dictate otherwise. Greater risk should be taken by the TAC during drilling operations to assure that all objectives for the well are attained. In this way the TAC achieves its long-term objectives by increasing its short-term risk. Furthermore, designating the $C R$ as the only individual with authority to change, amend, or modify any of the terms of a subcontract could lead to problems and costly delays. The relative element of risk is discussed in more detail in Section 5, Part D of this report.

\section{Recommendations}

In the event that the CR is not available, it is recommended that other individuals such as the TR or FTR have some authority to modify the subcontract so the drilling subcontractor's work can continue without excessive delays. Authority to modify or change the subcontract up to a certain percentage of the total contract amount should be given to the TR or the FTR. If the FTR has the authority to change some elements of the contract up to a prespecified amount, a greater risk is assumed by the TAC in the short term. However, adequately trained and experienced FTRs will use this authority to build wells that meet more of the primary objectives. Thus, the overall risk to the project is reduced in the long term.

Subcontractors perceive high risks to themselves because the drilling contracts are overly complicated. The subcontract including attachments to the RFPs should be thoroughly reviewed and any documents that are not absolutely necessary should be removed. Further discussion regarding the RFPs and attachments thereto appears in Section 6, Part A of this report. 


\section{UPGRADING QA/QC}

\section{A. Training Requirements for FTRs}

The need for training of the FTRs was well recognized in both written guidance and in discussions with Gerald Lindsay on how the skills of a potential FTR are assessed and the ways they can acquire the necessary skills to carry out their function. The list of SOPs that should be well understood by an FTR is clearly stated in the Albuquerque Operations Manual. The content of these SOPs is voluminous and, although most of the materials appear to be accurate and reasonably well documented, some of the guidance on monitoring well design and construction is limited and occasionally in error. These latter points are addressed in Section 4, Part B of this report. No attempt bas been made, however, to thoroughly analyze the content of all the pertinent SOPs.

Gerald Lindsay informed the ITR Team that he personally interviewed all new FTRs as to their experience and capabilities before they were allowed to work. Some of the FTRs have worked at many UMTRA sites, and once certified by Mr. Lindsay, were no longer questioned for contract work after the first project. Unfortunately, the results of the interview process that might indicate the strengths and weaknesses of the FTR candidate were not recorded, nor is there any formal indication of specific guidance given to the candidates for specific remedial study by Mr. Lindsay or by the other people associated with the site such as the SM, TM, Site Engineer (SE), SH, CR, Health Physicist (HP), Health and Safety Representative (H\&SR), or Quality Assurance (QA) staff. Similarly, items each SM, TM, SE, SH, CR, HP, H\&SR, and QA should address with the FTR are listed in Section 14.1.2 of the Operations Manual, but no formal checklist is filled out. Thus, no formal analysis of the effectiveness of the training requirements is evaluated. It is up to the individual FTR to clarify any issues with the TR, but this interview apparently is not required. After the interview with Mr. Lindsay, each FTR was given a complete set of pertinent SOPs, along with the applicable statement of work (SOW). The type of continuing oversight of the FTR by the TR (Mr. Lindsay) during the drilling process and well installation is clearly indicated in the procedures manuals.

The responsibilities of the FTRs are stated in Part 3.0 in Section 14.1.2 of the Operations Manual. In general, as a representative of Jacobs Engineering, they are to observe the drilling operations to make sure the SOW is followed. In Parts 3.1 and 3.2, the FTR is asked to "provide technical direction" of the field work (to the subcontractor). In Part 3.3, however, the FTR is told to "not direct or control the procedures or the physical conduct of the subcontractor." Thus, guidance given in Part 3.0 is not clear on the extent the FTR can direct or control the drilling and well installation operations.

Recommendations

It is recommended that these observations be used in the development of a more formal and documented process for the preparation of the FTR's to perform their field duties. 
Suggestions for improving the clarity of the FTR's field responsibilities and the extent the FTR can control the subcontractor are presented in Section 5, Parts B, C, and D of this report.

\section{B. Current Well Design and Construction Technologies are Inconsistent with Future Demands Dictated by the Observational Method}

It is evident in listening to presentations by Gerald Lindsay and others that the reason for some past well failures can be attributed to inappropriate design and construction standards. Because of the small diameter of these wells and the limited demands on the use of these wells, the design and construction failures have not posed significant problems. Future wells, however, will be deeper and larger diameter and must be far more efficient to meet the objectives of the observational method. It is necessary to define the criteria for successful wells in the observational method recently adopted by UMTRA. The observational method is an active approach to site remediation in which various techniques are tried to mitigate the contamination. Results are then evaluated and appropriate adjustments are made in the remediation scheme.

UMTRA wells must fulfill several functions in the observational method. Each well must produce water samples that will yield accurate chemical analyses. The wells should be constructed so that stratigraphic information can be obtained by one or more geophysical methods. Wells must be hydraulically efficient to maximize yields when used as extraction wells to minimize the number of wells needed to remove contaminated groundwater. Maximizing yields also minimizes the time required to take a valid water sample. And lastly, all wells must have a useful life of 30 years or more to meet regulatory requirements. Each of these criterion can be achieved easily in wells that are 4 inches in diameter or larger. Only some of the criteria cited above can be met if the well is 2 inches in diameter. Therefore, as the demands are broadened for wells used in the observational strategy, the desirability of 2-inch wells should decrease substantially.

It is not within the scope of the ITR investigation to evaluate in detail the current well designs and construction standards used in the UMTRA project. A brief review of the Shiprock Contract for Monitoring Wells dated January 28, 1993 (Exhibit A) and a handout prepared by Gerald Lindsay for the ITR meeting, suggest, however, that unrealistic and often impractical contract conditions are being stipulated. Preempting the use of several viable drilling procedures or tools on obviously invalid bases creates greater difficulties for the TR and FTR, as well as the subcontractor, in completing a successful well. Similarly, using certain types of prepacked screens incorrectly has led to well failures. In some cases, conditions are set that seem to demonstrate the lack of drilling experience on the part of the contract author(s). For example, the requirement that one or more drill collars be used to keep the borehole plumb is normally quite unnecessary for such shallow boreholes. Drill collars are required, however, for boreholes that are hundreds of feet deep. 
An example of unrealistic expectations demonstrated in the contract is the suggestion that air is the preferred drilling fluid for use with a conventional rotary rig in drilling coarse terrace deposits. Coarse terrace deposits are normally so unconsolidated that they could never be drilled "open bole" using air. But if the rig is equipped with a casing driver, it would be possible to drill with air. No mention is made, however, of the need for this equipment if air is used.

Another example in the contract demonstrates poor judgment in specifying the use of a 2inch well design. The sand, gravel, and boulders in the terraces will be difficult to drill and rigorous development will be required because bentonite will surely be used as a drilling fluid additive to water. The use of a frzgile 2-inch PVC prepack screen and casing in this type of terrane is not good design practice (although Mr. Lindsay vigorously defends the use of 2-inch monitoring wells in a handout given to the ITR committee). The well should be a minimum of 4 inches in diameter, constructed with a continuous-slot stainless steel screen, and either Schedule 40 PVC or thin-walled stainless-steel casing (assuming low carbon steel casing could not be used). A 4-inch diameter well allows easy development, permits the use of borehole geophysical tools, and reduces the chances for broken screen or casing in this difficult terrane. Prepack should not have been specified for the screen because development will become much more difficult in an aquifer that ordinarily can be developed easily when a continuous-slot screen and appropriate filter pack are used. In addition, the use of prepack screens will decrease specific capacities, increase water sample collection times, and reduce the well's effectiveness as an extraction well.

Other conditions set out in the contract also limit the success of the wells. Eliminating the use of dispersants (polyphosphates) for the removal of bentonite during development makes no sense because all the dispersants are removed during development and most wells drilled with bentonite will be much more efficient as a result. Prohibiting the use of biodegradable polymers is also inconsistent with producing hydraulically efficient wells. Research and experience have shown that development can almost be eliminated in certain cases if a polymer is used as the drilling fluid additive. Normally, the polymer is completely broken down during development by the addition of chlorine or other chemicals. Any effect from these chemicals or polymer break-down products would dissipate rapidly because of the large volume of water removed from these higher capacity wells during development and pumping. Over the past 25 years, thousands of wells have been drilled using polymers with no bacterial problems at all. Therefore, exclusion of these materials is inconsistent with one of the primary objectives of the UMTRA program - that is, water samples having low turbidities.

The great emphasis (guidance) placed on cement grout in the contract suggests the occurrence of past well failures caused by cement (calcium) entering the screened area of the well. It is virtually impossible for cement residues to reach the well screen zone if the filter pack is run 3 to 5 feet above the top of the screen with at least 2 feet of finer sand added over the pack and at least 2 feet of bentonite pellets placed over the sand seal. If 
the Shiprock Contract is an indication of UMTRA practice, the use of fine sand seals over the filter pack are not specified as they should be.

Other examples of conditions set out in the contract such as eliminating the use of cement pads at the well head because the grout seal around the casing is already sufficient, recommending "thinned" bentonite drilling fluids for the wrong reasons, and eliminating the use of centralizers around weak, flexible 2-inch PVC casing because of fears of voids in the grout (cement or bentonite) seal all need to be examined in light of how common-sense thinking must be applied to the UMTRA project. To be sure, certain states may have regulations against the use of some of these drilling fluid additives or phosphate. The rules were often adopted with little or no real field information. Therefore, UMTRA must push the agencies to allow certain procedures to be used so wells can be completed successfully.

It is equally important to establish criteria for a successful well as constructed for the UMTRA program. At the moment, wells whose screens are completely filled with sediment are somehow considered "successful!" This idea of "success" is misguided and falls well outside normal quality assurance standards for the entire water and monitoring well industry.

\section{Recommendations}

From the brief analysis made above, it is clear that some changes in well technology and drilling techniques should be undertaken as demands on the TR, SH, and FTRs become greater in the future. They will need to acquire additional information and experience on a much broader range of well technologies. It does not make sense any longer to limit the range of available technologies as is currently being done. In fact, there appears to be an effort to minimize the quality of the products used (such as screen and casing), even though the cost of these products is a small part of the total drilling and well construction project. The options for high-quality products and procedures must be utilized to overcome current deficiencies. These options are given in standard reference works such as Groundwater and Wells, 2nd Edition (Driscoll, 1986) and Practical Handbook of Ground-Water Monitoring (Nielsen, 1991). All FTRs and Trs should be familiar with guidance presented in these and other references.

In the future, most, if not all, monitoring wells should be at least 4 inches in diameter. Costs for wells will be marginally higher, but the overall usefulness of the wells will be increased substantially. Four-inch and larger diameter wells, for example, can be easily and effectively developed with standard tools to produce maximum bydraulic efficiency, accommodate most geophysical tools that help define the stratigraphy and the volume of water present in the formation, and yield water samples that represent actual water chemistry conditions in the aquifer. On the other hand, it is difficult, if not impossible, to develop 2-inch wells in some formations, most geophysical tools cannot be accommodated, and water samples often contain higher solids content than desirable, leading to inaccurate chemical analyses of the water. 
As stated in Section 5, Part B of this rejort an FTR with sufficient training and experience should be allowed maximum leeway in terms of both the design and construction to make the necessary adjustments. Prepacked screens, for example, may be a design alternative, but they constrain the FTR in making necessary (or desirable) changes in slot size and filter pack if conditions are not the same as predicted. Furthermore, development using a prepacked screen will seldom be as effective as that achieved using an individually installed pack. In general, inflexible designs or construction procedures will hamper the ability of the FTR in achieving the most satisfactory well.

Unrecognized errors in proposed design or construction procedures are even more debilitating. The TR and FTR (if known) should consult with potential bidders to establish practical criteria for every aspect of the project. Contracts should be based on these informal discussions so no unrealistic specifications are written into the contract. It is especially incumbent on the TR to have a state-of-the-art understanding of well technology so that he or she can guide a subcontractor to better solutions than might ordinarily be achieved. Currently, recommendations on screen type, slot size, casing and screen diameter, filter pack selection, and development methods are not "state of the art" and, in some cases, are simply wrong. As a result, some UMTRA wells have been difficult to complete, others have failed to achieve normal operating objectives, and some have failed altogether.

\section{Lack of Finished QAIP}

Jon Blount gave a presentation detailing the progress with the UMTRA QAIP. In that presentation, be stated that no quality assurance plan has been available to the TAC staff up to this point. The only documentation available to guide the quality of project procedures has been the SOPs. A draft QAIP currently is being revised and should be completed later this year. Copies of this draft document were provided to the ITR Team.

The ITR Team believes that the lack of quality-assurance guidance to date is a serious deficiency. Effective guidance must be provided to assure that appropriate procedures are followed so that data quality objectives are met. Furthermore, the lack of general data quality objectives for the project seriously hinders evaluation of the quality of procedures.

The development of the QAIP will serve to assuage some of these difficulties in the future; however, the draft of this document does not give adequate guidance sufficient for the groundwater program. In general, it appears that there is a misunderstanding about which information should be in the QAIP and which should be in the SOPs. For some procedures, for example aquifer pumping tests, the reader is directed to the appropriate SOP for guidance in quality assurance measures. For other procedures, such as water level measurement, the QAIP contains better procedural guidance than relevant SOPs. In this case, however, the information about calibrating water level measuring devices is located in two places (on page 9-3 of Section 9.1.2 and on page 9-5 of Section 9.1.3), whereas no information is given in Section 7.3 which presents information about the measurement of 
hydrologic parameters. In that section, the reader is told only to consult the SOPs on "aquifer pump tests" and slug testing. Yet, those SOPs contain no guidance on how to calibrate measuring devices, and only limited guidance on water level measurement.

The draft QAIP also focuses predominantly on assuring the quality of water samples and analytical results with minimal treatment of $Q A / Q C$ procedures for other field activities such as well installation and water level measurement.

\section{Recommendations}

High priority should be given to the completion and issuance of the QAIP, which should set the data quality objectives for the project. It should provide guidance for assessing whether SOPs are adequate and that they are being followed. Because the SOPs are used to guide technical activities in the field, they should contain the basic QA/QC procedures so FTRs, SHs, and others have this guidance readily accessible when it is most needed.

\section{Lack of Use of WITS Database}

M. B. Leaf provided a valuable overview to the WITS database. Rich Papusch described the SPEAR database. As we understood from these briefings, the WITS database is separate from the SPEAR database and contains substantially different data describing wells and supporting information. However, information contained in the WTTS database is required for accomplishing a number of site activities that have been critical to the project in the past and will be especially critical to the future groundwater program. For example, the status of well permits and site-accessibility agreements are essential to the performance of duties required of the SH and the FTR. Some of the TAC members, however, indicated that they do not use the WITS database. Based on comments made by some of the TAC staff, we believe these people represent many others who could be using this database but aren't because it is separate from the SPEAR database. Although perhaps reasonable at one time, it appears that there no longer exist sufficient reasons for keeping the two systems separate and there are now sound reasons for merging the two.

Recommendations

We recommend that all reasonable efforts be made to merge the WITS database with the SPEAR database as soon as possible. This action will give each SH and TR easier access to needed information as the next phase of the project gets underway.

Although the above suggestion seems to make sense, there may be economic constraints. Thus, we recommend further investigation into the cost of merging these two databases before the project is started. Should the TAC conclude that this effort would be too costly, we recommend that efforts be made to educate appropriate TAC staff in the value of the information contained in the WITS database and how to gain access to it. As a result, those who could use the information in the WITS database would at least be more familiar with its availability and accessibility and thus, may use it more frequently. 


\section{E. No Site Visit by Some Site Hydrogeologists}

Various TAC staff indicated that some Shs have not been to the sites for which they are responsible, whereas others have visited only after substantial work has been completed. The QAIP, though now only in the process of being completed, contains the following guidance on page 7-11 of Section 7.2.1: "If possible, visit the study area to perform a preliminary reconnaissance. During this reconnaissance, study the topography and geological exposures, and gain permission for land access. If a site visit is not possible, contact appropriate agencies and landowners through correspondence."

The $\mathrm{SH}$ is responsible for the accurate representation of the geologic and hydrologic characteristics of the site to other members of the UMTRA project staff. Yet, without having travelled to the site, that person is limited in fully understanding the site. In fact, one of the first things a skilled field geologist, bydrologist, or hydrogeologist must do to gain a reliable perspective of the conditions at a site is to visit the site and examine visible conditions first-hand. Previous site studies, maps, photos, or other site-specific information can provide valuable insight into site characteristics, yet they cannot replace a site visit. Only with such a visit can the SH observe the subtle physical features at the site and their relationship to the context in which the site exists.

An accurate understanding of the geologic and hydrologic conditions at the site will prove even more important during the groundwater restoration phase of the project. The ease of reaching decisions about remediation options and the effectiveness of those options during the groundwater program phase will depend on how well the SH has understood and described the groundwater flow conditions at the site. Furthermore, the observational approach to be used in the future will require that site conditions and interaction of site elements are observed first hand by the SH.

\section{Recommendations}

The ITR Team believes that site visits by the SH early in their involvement with a site are important to the success of the groundwater program. Although travelling to the site adds to the cost of the project, it must not be considered optional. The importance of a site visit needs to be stated clearly in the QAIP. In the current draft form, the language in the QAIP is insufficient to convey this importance. The final version of the QAIP must stress the significance of a site visit more strongly.

\section{PARAMETERS OF FTR POSITION}

\section{A. More Rigorous Assessment of FTR Skills is Needed}

Gerald Lindsay (the TR) outlined the procedures used to assess the skills of a new FTR. In general, the assessment consists of an informal conversation between Mr. Lindsay and the FTR, during which the well contract is discussed. No checklist on applicant skills is 
filled out during this conversation, nor is there any record kept of the results of the FTR evaluation. The TR does send out or give the FTR a checklist of documents (SOPs) that apply to the work and the appropriate people to be contacted. No followup procedure is given in which the TR tests the FTR's knowledge of the pertinent SOPs or QA procedures. A minimum of three days of training are given to FTRs who have had no experience in water well drilling before they are assigned field work. Again, no evaluation is done of the training. Both initial and ongoing evaluation of the FTR apparently lies only with the TR. Formal, written evaluations of the FTR by the TR, subcontractors, or anyone else connected to a specific project are not done.

Current procedures in evaluating the FTRs are not adequate for future work and, in fact, were probably not adequate for past work. Descriptions of well failures, for example, suggested that competent FTRs could have managed the problems more successfully. But, in fairness, the limits placed on the FTR in terms of directing the project coupled with mistakes in contract specifications may have placed the FTR in a no-win situation.

\section{Recommendations}

More rigorous assessment of FTR skills both initially and long term are desirable to assure maximum value in well construction and provide personal guidance to the FTRs on their strengths and weaknesses. Several steps should be taken to formalize the evaluation process. Results of these evaluations should become part of the FTR's personnel file. Use of these records by the TR will assure selection of the best candidates for follow-on work.

The initial interview of the FTR by the TR should be accompanied by a checklist that provides a record of the FTR's skills. This checklist should be expansive, covering many of the situations encountered in drilling and the skills needed to meet these challenges. Discussion of the contract can be used as a vehicle to check on the past experience of the FTR. This formal inventory of skills can be used to guide the new FTR on what he or she must learn in addition to the guidance provided in the SOPs. Copies of the skill inventory should be sent to the relevant SM, SH, and CR.

At the time of the initial interview for a new candidate, the TR should construct a list of possible deficiencies and the ways these deficiencies can be overcome by the FTR candidate. A time of completion should be established by the TR. Currently, FTRs with only geotechnical-related drilling experience are able to qualify for water well (monitoring) drilling in as little as three days. It is doubtful that this length of time was sufficient to fully qualify many of the FTRs, but in light of the much more rigorous technical requirements demanded in the future, a three-day training period is entirely unsatisfactory. The TR should locate more qualified FTRs or provide much more rigorous training for them. Ultimately, the TR's job will become less burdensome.

After the new FTR has undertaken the prescribed training, reviewed the relevant SOPs, and talked with the various interested parties, the TR should arrange a second formal interview in which either a short examination is given or previous weaknesses are checked verbally 
in detail. The evaluation by the TR could be facilitated by collecting evaluations done by the SM, SH, and CR during their contacts with the FTR. In addition, the TR should challenge the FTR on anticipated conditions during drilling and judge how the FTR would handle various types of changed conditions. A record of this second interview should be retained as part of the personnel file.

After drilling commences, the TR should visit the site to verify the effectiveness of the FTR, especially with the subcontractor (driller). This is also an excellent time for the TR to coach the FTR on possible technical approaches that may be applicable to the well. The TR should write up a short note giving his or her appraisal of the FTR's effectiveness and enter it into the personnel file.

Upon completion of the well, the FTR's job performance should be evaluated by the subcontractor, SM, and SH. The results of this evaluation must be discussed with the FTR and any additional education should be specified. A summary of the record should also be placed in the personnel file.

Implementation of the suggestions made above will add a burden to the TR, but the current level of qualification and training appears to be insufficient to meet future challenges. Ultimately, more fully qualified FTRs who have the authority to make significant decisions in the field will reduce stress on the TR and maximize the opportunities for successful wells. Over time, the TR may also want to train some Shs for the FTR position to capitalize on the SH's understanding of site hydrogeology and their overall interest in the site.

\section{B. Lack of Decision-Making Ability of FTRs During Drilling}

Information presented by Gerald Lindsay and guidelines given in the Albuquerque Operations Manual suggest that FTRs have limited ability to change well specifications or aspects of the drilling operation in the field in response to changed conditions. Apparently, only the CR can redirect effort or change a contract. Review of Mr. Lindsay's comments indicate that the limits imposed on the FTR may have led to drilling failures or the construction of less satisfactory wells. Several problem areas are evident, ranging from the rigidity of the contract process in regard to responding to changed conditions, to the technological limits imposed on the FTR.

The first problem concerns the way FTR responsibilities are expressed in Section 14.1.2, Part 3.0, in the Operations Manual. In Parts 3.1 and 3.2, it is clearly stated that the FTR is to provide technical direction to the subcontractor (the driller) and direct all field work. Yet in Part 3.3, the FTR is told not to direct or control the procedures or the physical conduct of the subcontractor. It is obvious that the FTR should not become a working member of the drilling crew, but the FTR must be able to adjust certain aspects of the drilling operation or even suggest alternate physical procedures as conditions warrant to complete the borebole or install the well casing and screen successfully. The guidance given 
in Part 3.0 is ambiguous because it tells the FIR to take an active role in the well construction process, but also limits the FTR in controlling the physical procedures used by the driller. A strict reading of this ambiguous guidance suggests that technical direction given by the FTR is confined only to enforcement of specified contract provisions. Thus, the FTR is not allowed to change drilling or well installation procedures outside of those identified in response to changed conditions. If this is the case, a much higher incidence of well failures can be expected to occur in the future as wells become more complicated.

The FTR responsibilities in Part 3.0 also must be clarified. If the FTR is a representative of Jacobs Engineering, he or she is acting as an in-field consultant on the drilling project. In this same position, a professional consultant will usually take a much more active role than that apparently assigned to the FTR. A consultant controls the project to assure its success, and in that process, must be able to alter contract provisions that would impede the project. If the FTR has the same qualifications as a typical hydrogeological consultant versed in drilling operations, he or she must be given the same latitude to accomplish the desired result. In this process, it is clear that the primary responsibility for successful completion of the well shifts somewhat from the TR, CR, and SH to the FTR. If the realignment of responsibilities is not done, well failures will increase in the future as well design and construction procedures become more complex. Shifting more of the responsibility to the FTR, however, will require greater verification of skills than may currently exist and the need for training may also increase.

Illustrating ways in which the FTR may work with the driller would be belpful guidance for the FTR (and TR). Typical professional consultants, for example, will normally control drilling fluid viscosities, drilling rates, bit use, installation of the screen, placement of filter pack, well seals, and type and length of development. These are areas in which actual field conditions may dictate drilling and installation procedures that differ from those given in the contract. The FTR must be able to give appropriate and timely directions in the field on these issues without necessarily contacting the TR, SM, SH, or CR. The FTR must discuss thoroughly with the subcontractor, however, any changes in scope or variations from the contract to which the subcontractor objects on the basis of safety to his or her rig or crew or the ability to complete the well installation successfully.

\section{Recommendations}

Expanding the role of the FTR in controlling the well drilling operation will require greater demonstrated expertise on the part of the FTR in all areas of well drilling methods and rigs, as well as well installation and completion techniques. Guidance in the Operations Manual should be enhanced along with the level of experience required. If a new FTR is employed, formal technical training of the individual is recommended before being assigned to field work. Furthermore, FTRs should be tested for their ability to communicate effectively, especially with drilling crews. Last of all, any guidance that is given in the Operations Manual must be unequivocal and current ambiguities must be removed. 
If the position of the FTR is enhanced so that decisions can be made in the field, field-office communications capability must be improved electronically between the FTR and those with whom he or she must consult, that is, the SM, SH, TR, and CR. This issue is addressed in Section 2, Part D; its importance in producing good wells cannot be over stated.

It is also vital that the technological options available to the FTR be maximized by opening up the bidding process to accommodate both small and large firms. Limiting the use of technical approaches increases the chance that wells will be less useful. It is not sufficient that a subcontractor merely meet what is specified in the contract. Contract awards should also take into account the versatility of the driller to respond to varying conditions.

In summary, a change in the level of responsibility assigned the FTR is vital if the much more complicated wells that are to be constructed as part of the proposed observational strategy are to be successful. The ability to respond to this higher level of responsibility will depend on the technical skills and training of the FTR, the versatility of the subcontractor, enhanced communications among all parties involved in the process, and the level of risk willing to be assumed by the TAC during drilling and well construction. The element of risk is addressed in Section 3, Part C.

\section{Lack of Guidance on the Flexibility Given to the FTR as to How Wells are to be Constructed Under the Constraints of the Contract}

In the Albuquerque Operations Manual, Section 14.1.2, Part 3.0, concerning the responsibilities of the FTRs, guidance is given to the FTRs to provide technical direction to the subcontractor, but not to control "the procedures or the physical conduct of the subcontractor." The ambiguity in these statements is discussed in Section 5, Part B of this document. The focus in addressing the issue of guidance bere is on the limits placed on the FTR in directing the physical conduct of the procedures (Part 3.3).

Normally, a drilling superintendent would be involved in establishing the methods used to drill a well. This is not the case for the FTR, although Mr. Lindsay indicated the terms of the contract were discussed with the FTR. Apparently, this talk occurs after the contract has been prepared and the bid let and relates more to qualifying the FTR to perform the supervisory function. Thus, the FTR is asked to carry out a set of instructions with little or no input as to their practicality.

Under Part 3.2 in the Operations Manual, the FTR is permitted to "designate hole locations, depth and completion zones, and sample types and depths." Certainly, these potential acts involve controlling the physical conduct of the driller so as to respond adequately to field conditions. What is unclear in Part 3.3, which prohibits control of the physical conduct of the subcontractors, is the nature of the unspecified physical limits placed on the FTR in regard to driller operations. It is appropriate that the FTR not become part of the drilling crew in performing actual physical operations, but it is equally inappropriate that the FTR 
would have no control on the viscosity of the drilling fluid, the rate of bit penetration, the withdrawal rate of tools or drill rods from the well bore, the location of the tremie pipe during installation of the filter pack or cement grout, the selection of optional development methods if original methods are unsatisfactory, and the length of time required for adequate development. Each of these actions is a clear example of how the FTR can legitimately control the physical conduct of the subcontractor.

Control exercised by the FTR during well drilling and installation must be done with caution and, ideally, with agreement on the validity of the FTR's suggestions by the subcontractor. The driller understands the mechanical operations of the rig better than the FTR, but the FTR must assume responsibility for meeting all of the objectives designated for the well and, in the process, will often alter the "normal" operation of the rig. As a result, collaboration between the driller and the FTR is essential for successful well construction and must be based on mutual respect.

\section{Recommendations}

In constructing a well, the subcontractor is constrained by wording in the contract. Similarly, one of the primary duties of the FTR is to enforce specifications in the contract. But the FTR, unlike the driller, should be free to change certain control or operational provisions to respond to actual field conditions or to increase the efficiency of the drilling or well installation process. By necessity, most, if not all, of these changes during drilling or well installation will involve modifying some physical or sometimes chemical operation of the subcontractor. The FTR should be informed by the TR that altering some of the physical operations will be necessary from time to time. Specific examples of these actions should be discussed with the FTR by the TR. Furthermore, wording in Part 3.3 should be modified to clarify the latitude given to the FTR in maximizing the effectiveness of drilling and well construction operations.

\section{Ambiguity in Job Contract as to the Control that can be Exercised by the FTR}

It has been argued above that the FTR, once trained and fully qualified, should be given more responsibility in directing the efforts of the driller in constructing the most successful well possible. It is true that the risks taken by JEG will increase initially during the construction phase, but are reduced later as more functional wells produce better data, provide greater versatility, and, in general, meet more of the task's objectives. Effective integration of the FTR into all aspects of well construction will depend on the strength of the relationship the FTR can establish with the driller. If this relationship is one of mutual respect, the FTR can maximize "physical" control of the operation. If the relationship does not exist, the FTR has almost no control. It is this ability to exert physical control that must be clarified, especially as the responsibilities of the FTR are stated in Section 14.1.2, Part 3.3, in the Field Technical Representative's manual. 
In general, the guidance given in the manual relates to the myriad "duties" to be performed by the FTR in making sure the SOW is performed within standards set out in the relevant SOPs. Examples of "physical" control are given in directives relating to locating each borehole, intervals to be cored, depth of each borehole, and construction of monitoring wells. It is emphasized that the FTR cannot control or direct the physical conduct of the subcontractor, however, nor can any action by the FTR serve to increase the total amount of the subcontract.

Control of the driller's physical activities may be vital in the successful completion of the well. The FTR should have the authority, for example, to demand that optimum hydraulic pressures are consistently maintained in the borehole (mud rotary rig) during drilling and until the casing, screen, and filter pack are installed. FTRs should be able to control the rate of bit penetration if the driller is using excessive pull-down pressures or speed of rotation to make sure the hole is round. Up-hole drilling fluid velocities also should not become excessive or borehole washout might occur, especially in air drilling. These examples of physical control exerted by the driller should really be under the control of the FTR. Although the driller may have his or her hands on the levers, the FTR has the right (and obligation) to control how the levers are used.

Thus, physical control, per se, is quite acceptable and should be well within the duties of the FTR. What is not acceptable is for the FTR to take over the physical running of the rig, that is, actually pulling the levers that control the speeds, pull-down pressures, or circulation rates. Mechanical operation of the drill rig, auxiliary compressor, and grouting equipment related to drilling and well installation should be done only by the driller.

\section{Recommendations}

Making clear what "physical control" actually means will be important if the FTR is to gain a greater role in assuring satisfactory well construction of UMTRA wells. It will also mean the FTR must be better trained and involved, to the extent possible, in formulating well design and construction principles for UMTRA to maximize continuity in a well project. Furthermore, some Shs should be given the opportunity and training over time to assume the enhanced responsibilities of the FTRs. Their familiarity with the site and their general interest in the ground suggest some Shs would become skillful FTRs. Lastly, great effort should be expended in developing the communication skills of the FTRs. Subcontractors are, by nature, proud, independent entrepreneurs who often don't take direction well, especially from those whom they perceive to be desk-bound scientists and engineers. To assure successful well construction every time requires a well-developed working relationship between the FTR and driller.

\section{E. Lack of Formal Long-Term FTR Association with the Site}

Results of the ITR interview with Gerald Lindsay indicated that often FTRs do not bave a long-term involvement with a particular site. Although some effort is made to use the 
same FTR consistently at a site, this is sometimes not possible because of demands placed on FTRs in their primary workplace.

Parts 3.1 and 3.2 of Section 14.1.2 of the Albuquerque Operations Manual state that the FTR must provide technical direction of the subcontractor and the field work at a site. Not only must the FTR represent the TAC in the field but the FTR must represent the field conditions to the TAC, more particularly the site TR and the SH. Thus, the FTR serves as the primary technical contact with the subcontractor and must observe and report on-site technical and operational conditions accurately and consistently. The TR and the SH rely heavily on the information provided by the FTR to support sound conclusions and make appropriate decisions. The information provided by the FTR must be consistent for these conclusions and decisions to be reliable.

\section{Recommendations}

If the FTR assumes more responsibility for on-site subcontractor direction under the groundwater program it will become even more important for this person to maintain an ongoing familiarity with the site. In addition, because the groundwater phase may require a more rigorous examination of hydrogeologic conditions, an awareness of the extent of previous site activities will help the FTR be more effective on site. For example, by baving previously provided technical direction during the installation of wells at a site, the FTR will possess knowledge of the subtle differences in the performance or reliability of a well for hydrologic testing.

All attempts should be made to use the same FTR on a particular site as the technical work at that sight progresses.

\section{CONTRACT MODIFICATIONS}

\section{A. Contract Provisions}

The Request for Proposal for Drilling and Monitor Well Installation at the Shiprock, New Mexico Processing Site (RFP No. 05-62350-R-93-0008) consists of 91 pages and is assumed to be typical of the majority of the drilling and monitor well installation RFPs. The RFP consists of a 2-page cover letter, 30 pages of work scope, a 4-page pricing schedule, and 58 pages containing a draft subcontract and "Representations and Certifications." Most drilling contractors are familiar with work based on a handshake or, at most, a signed letter of agreement. Although we have no knowledge regarding the percentage of firms responding to these RFPs, a much larger response would be expected if the RFPs could be simplified.

Recommendations

The ITR Team expects that simplifying the RFPs would result in more responses and could result in a significant cost savings to the project. RFPs could be simplified by separating the RFP into two volumes, with the scope of work and pricing schedule in Volume 1 and the 
draft subcontract and "Representations and Certifications" in Volume 2 or by not including the draft subcontract or "Representations and Certifications" in the RFP. These documents would then be presented only to the successful bidder for execution.

To demonstrate the type of RFPs that are being used by other government contractors for drilling services, attached is an RFP for geotechnical engineering and sampling prepared by MK Ferguson Company for the UMTRA project at Ambrosia Lake, New Mexico (Attachment A). It is suggested that this RFP be reviewed when evaluating bow to simplify the TAC's RFPs.

\section{B. The 100-Percent Set Aside for Small Business May Restrict the Construction of High-Quality Wells}

It is an ITR Team recommendation in Section 4, Part B, that most monitoring wells to be constructed in the future should be multi-purpose wells of 4-inch diameter or larger. This will enable not only monitoring of groundwater quality, but also allow for high-volume pumping to establish aquifer characteristics or pumping for treatment if required. Larger diameter wells generally require more sophisticated drilling equipment and specialized drilling procedures. It is doubiful that there are a sufficient number of small business concerns who own or have access to the necessary equipment. It is anticipated that future well construction contracts will be large enough to attract a number of drilling contractors who do not qualify as small businesses. Use of qualified larger contractors could result in higher quality wells at a reduced cost.

Recommendations

Small business set-aside drilling subcontracts appear to limit the number of offerors and could result in non-qualified drilling contractors installing the wells. This may lead not only to inferior well construction, but higher well-installation costs. It is recommended that future drilling contracts that involve specialty drilling rigs, specialized tools and equipment, or specialized expertise not be limited to small businesses. At present, the TAC may be specifying drilling methods or techniques that are not necessarily the best drilling method/technique to install the highest quality, reliable wells because they are aware that small drilling contractors are capable of installing wells by these methods. Utilization of the Becker Hammer drilling method, the dual-tube method, a Barber rig, or similar "high tech" methods may allow well installation at many sites without the need for mud rotary techniques. 


\section{Attachment A}

\section{MK-Ferguson Geotechnical Drilling RFP dated July 15, 1993}


ENGINEERS

AND

CONSTRUCTORS

MK.FERGUSON COMPANY

a MOAMBOON KMUDSEL companY

MEADOUARTERS OFFICE

ToO WEST 3RO STREET

COMTHND OHIO U $\$$ A CAT13.1406

MHONE. (216) B23-2000/TELEX Massiz

MEPLY TO MK.remguson COMPANY

AEMEDUL ACTIONS

CONTAUCTOA. UHTAM MAOJECT

$00 \times 9136$

ALLUOUEROUE. NEW MEXICO U S A B7119

July 15. 1993

SHB

4700 Lincoln Road NE

Albuquerque, NM 87109

Attention: Dave Tanner

SUBJECT: REQUEST FOR PROPOSAL TO PERFORM GEOTECHNICAL DRILLING AND SAMPLING

\section{REFERENCE: URANTUM MILL TAILINGS REMEDIAL ACTION PROJECT (UMTRA) AMBROSIA LAKE, NEW MEXICO}

Dear Mr. Tanner:

You are herety requested to submi: a proposal to perform Geotechnical Drilling and Sampling for the Ambrosia Lake. New Mexico Uranium Mill Tailings Remedial Action (UMTRA) site in accordance with the atrached Scope of Work.

Enclosed are the following ducuments for use in preparation of proposals for the subject bid package:

1. Scope of Wiork

2. Unit Price Sheet

3. Vicinity Man

4. Figurc 1, Sample Laiations

5. Tahle 1, Comrdinart: \& Depths of Sample Locations

6. Certificate of Insurance Form

NOTE: Certificate of Insurance in the amuunt of $\$ 1,000,000.00$ is a mandatury requirement (General Liability and Auromnhile Liability; excluding Builder's Risk). We. as MK-Ferguson Company and the Department of Energs; are to be named as additional insureds. Cercification of required insurance is to be turnished atter award and prior to commencing work

Work has been tentatively scheduled to hegin August 30, 1993, subject tu site conditions.

Please fili in the unit price sheet enclosed for use in preparation nf your proposal. 
Mr. Dave Tanner

Request for Proposal

July 15, 1993

Page Two

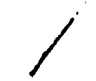

Proposals will be due July 29, 1993, no later than 3:00 P.M. (local time).

Proposals submitted by U.S. Mail should be sent to the following address:

MK-Ferguson Company

P.O. Box 9136

Albuquerque, NM 87119

Attention: H.M. Langlois

Proposals delivered by hand should be brought to:

MK-Ferguson Company
2309 Renard Place, S.E.
Suite 300
Albuquerque, NM 87106
Attention: H. M. Langlois

Should you have any questions or comments regarding this package, please contact the undersigned at (505) 246-2511.

Sincerely,

MK-FERGUSON COMPANY

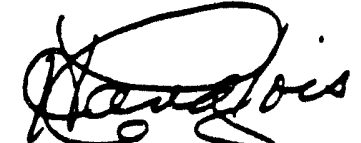

Helene M. Langlois

Purchasing Agent

HML/cpr

Enclosures

cc: Karl Hamilton, w/enc.

D.P. Bradley, w/enc. 
SCOPE OF WORK

GEOTECENICAL DRRLLNG AND SAMPLNG

UMTRA PROJECT - AMBROSIA LAKE, NM 


\section{TABLE OF CONTENTS}

\section{Page}

1.0 Scope and Objectives 1

2.0 Location 1

3.0 Drilling and Sampling 1

3.1 General 1

3.2 Surface and Subgrade Conditions 1

3.3 Special Conditions 1

3.4 Survey 2

3.5 Hole Locations and Depths 2

3.6 Rig 2

3.7 Sampling 3

3.8 Field Procedures 3

3.9 Drill Hole Abandonment 3

4.0 Permits, Certifications, Laws \& Ordinances 4

5.0 Decontamination 4

6.0 Environmental Health and Safety 4

7.0 Compensation 4

Unit Price Sheet 5

Vicinity Map $\quad 6$

Figure 1 (Sample Locations) 7

Table 1 (Coordinates and Depths of Sample Locations) 8 


\section{SCOPE OF WORK \\ GEOTECHNICAL DRILING AND SAMPLING \\ UMTRA PROJECT - AMBROSIA LAKE, NM}

\subsection{SCOPE AND OB.IECTIVES}

This project is conducted by MK-Ferguson Company, the Contractor, to collect soil samples from the Ambrosia Lake, New Mexico uranium mill tailings pile. The Contractor will provide technical direction at the site.

The work to be performed by the Subcontractor will include drilling and sampling (split barrel samplers) of boreholes as required by the Contractor.

\subsection{LOCATION}

The Ambrosia Lake UMTRA Site is located 25 miles north of Grants, NM and approximately 100 miles northwest of Albuquerque, NM. (See attached map).

\subsection{DRILLNG AND SAMPIING}

\subsection{General}

Drilling and sampling for this Subcontract are subject to the specification clauses contained in this scope of work. Failure to comply with these specification clauses is considered a breach of the Technical Specifications and default of the performance of this Subcontract by the Subcontractor.

\subsection{Surface and Subsurface Conditions}

The area to be investigated is the top 20 feet of material beneath the $5: 1$ slopes of the tailings embankment. Both clayey and granular soil may be encountered during sampling.

\subsection{Special Conditions}

The tailings embankment is located in a radiologically contaminated area with radioactive surficial and subsurface materials. 


\subsection{Special Conditions (Cont.)}

Protective clothing shall be required when sampling or handling the contaminated materials. The Contractor shall provide rubber overshoes, coveralls, gloves and (if required) respirators to all field personnel. However, other safety aids such as hardhats, boots, safety vests etc., shall be supplied by the Subcontractor to his personnel at no cost to the Contractor.

The Contractor will provide eight (8) hours of initial Health and Safety Indoctrination, Radiological safety training and will be on hand to monitor radioactive levels and to assist in monitoring the health and safety of the persons on site.

All Subcontractor personnel working on this project shall hold current certification of 40 Hour OSHA Training which includes Medical Qualification for respirator use. This shall be provided to the Contractor prior to starting the actual work on the site.

\subsection{Survey}

Survey work will be performed by others. The surveyor will provide ground elevations and mark each borchole location with a hub and lath.

\subsection{Hole Locations and Depths}

The exploration program will include sixteen (16) borings to a depth of twenty (20) feet. See Figure 1 for locations and Table 1 for coordinates.

\subsection{Rig}

The drilling must be capable of drill vertically while positioned on a 5:1 surface. The surface shall not be disturbed for leveling purposes. It shall be equipped to do the penetration test and sampling. The Subcontractor must supply all drilling equipment, including casing and sampler.

Except as noted below, a hollow-stem type auger or split spoon rig capable of drilling to depths of twenty (20) feet shall be used for all holes. The inner diameter of the hollow stem auger or split spoon shall be two (2) to three (3) inches. The hammer weight for driven semplers shall be a minimum of 300 pounds. 


\subsection{Rig (Cont.)}

The Subcontractor shall keep to a minimum the area of ground surface which is disturbed (within the constraints of practical and efficient completion of the work). Any drill rig or combination of drill rigs or other equipment may be used in the completion of this work if it (they) can be shown to be capable of meeting the requirements of this Subcontract. No drilling fluids shall be used.

All equipment/vehicles used on the sile shall be delivered in a clean condition i.e., no visible mud, grease and debris. The equipmentvehicles will be required to go through an initial radiological survey and safety inspection prior to entering the job site.

Prior to use of equipment on the job site, it shall be safety inspected and surveyed by the Contractor. Minimum requirements include, but are not limited to, operational backup alarm, fire extinguisher, operational brakes, evidence of annual crane inspection (which is required on all hoisting equipment) and any other applicable OSHA standards.

\subsection{Sampling}

A. Soil samples will be primarily obtained using ring-lined split bartel samples (Dames \& Moore U-Type sampler or equivalent).

B. The Contractor's personnel will extract needed samples from the drill barrels with the Subcontractors assistance.

C. Blow count data will not be obtained.

\subsection{Field Procedures}

At each designated location, the work consists of continuous drilling and sampling to a depth of twenty (20) feet. Samplers shall be cleaned (brushed, wiped, and or rinsed) as directed by the Contractor, before commencing each sampling drive. Supplies and wash water used to clean the samples will be disposed of on site as directed by the Contractor.

\subsection{Drill hole Abandonment}

The Subcontractor shall fill all drill holes as directed by the Contractor. All drill holes shall be abandoned and baclfilled with excavated material. 


\subsection{PERMITS, CERTIIICATIONS, LAWS AND ORDNANCES}

All permits, certificates and licenses required of the Subcontractor for the execution of his/her work shall be procured at no cost to the Contractor. The Subcontractor shall comply with all agency or governmental ordinances and regulations pertaining to the performance of the work.

\subsection{DECONTAMINATHON}

Due to the radioactive nature of the materiais, all equipment and tools shall be inspected by the health physics department at the completion of testing at the site. All equipment and vehicles found to be contaminated by radioactive materials shall be thoroughly washed/cleaned by others before leaving the site. Any personnel found to be contaminated by radioactive materials shall be required to wash/clean up prior to exiting the site. It is anticipated that cleaning can be accomplished by washing with water. Wash water will be provided by the Contractor. Any necessary decontamination work shall be performed at the stipulated standby time (hourly) rate.

\subsection{ENVIRONMENTAL HEALTH AND SAEETX}

The site is located in an area classified as having low-level radioactive contamination. The Contractor will provide a health physics trained technician on-site during the work to monitor the radioactive levels and to assist in determining the health and safety of the personnel on-site.

The Subcontractor shall provide the Contractor MSDS sheets for all chemical substances that will be brought on site for use during the drilling process. The Subcontractor shall provide all PPE required, as specified in the MSDS sheet, for all chemical substances which may be used.

\subsection{COMPENSATION}

Comperstion for all work will be made in acoordance with the paymem iterns listud or: the Unit Price Sheet. If the quantity of any item varies from the quantity listed in the schedule, the Subcontractor will be paid according to the unit prices. 

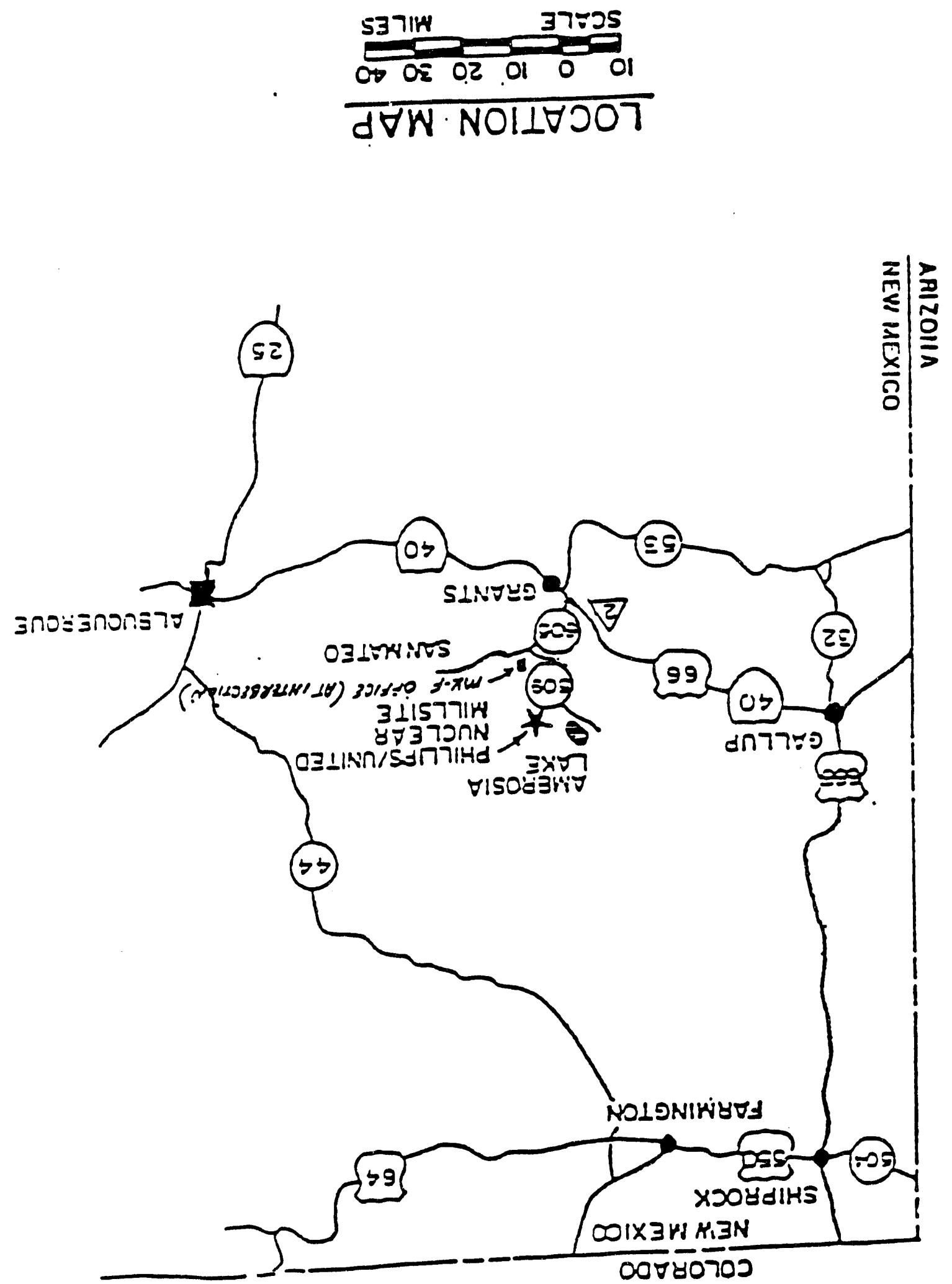
Figure 1

Sample Locations

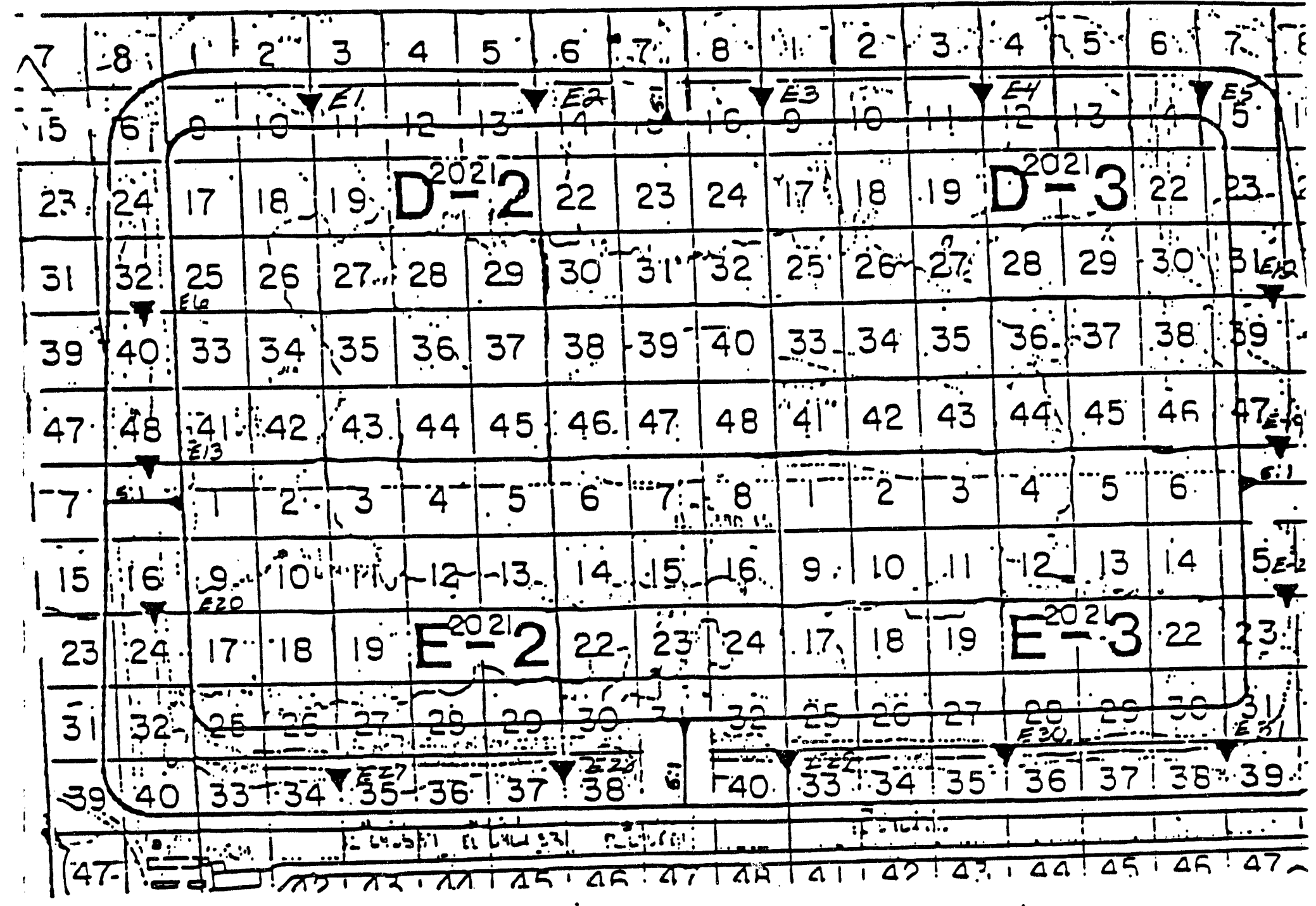

T-sample weations 
Table 1

Coordinates and Depths of

Sample Locations

\section{Coordinate}

Drill hole

No.
Northing

Easting
Total Depth

Sampling

(ft)

\begin{tabular}{llll}
\hline E-1 & $1,604,770$ & 509,300 & 20 \\
E-2 & $1,604,770$ & 509,705 & 20 \\
E-3 & $1,604,770$ & 510,200 & 20 \\
E-4 & $1,604,700$ & 510,650 & 20 \\
E-5 & $1,604,770$ & 511,000 & 20 \\
E-6 & $1,604,350$ & 508,950 & 20 \\
E-12 & $1,604,350$ & 511,230 & 20 \\
E-13 & $1,604,050$ & 508,950 & 20 \\
E-19 & $1,604,050$ & 511,230 & 20 \\
E-20 & $1,603,750$ & 508,950 & 20 \\
E-26 & $1,603,750$ & 511,230 & 20 \\
E-27 & $1,603,430$ & 509,300 & 20 \\
E-28 & $1,603,430$ & 509,750 & 20 \\
E-29 & $1,603,430$ & 510,200 & 20 \\
E-30 & $1,603,430$ & 510,650 & 20 \\
E-31 & $1,603,430$ & 511,100 & 20
\end{tabular}


companr 8 LETEA

\begin{tabular}{l}
$\begin{array}{l}\text { company } \\
\text { LETTEA }\end{array}$ \\
\hline $\begin{array}{l}\text { company D } \\
\text { LETIEA }\end{array}$ \\
\hline $\begin{array}{c}\text { company } \\
\text { LETTEA }\end{array}$ \\
\hline
\end{tabular}

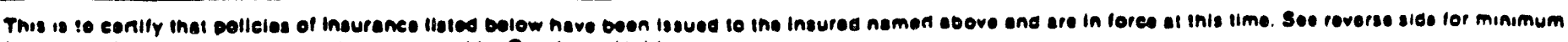
insurance. limils and endorsoments as ruquired oy Coniliesio Holdor.

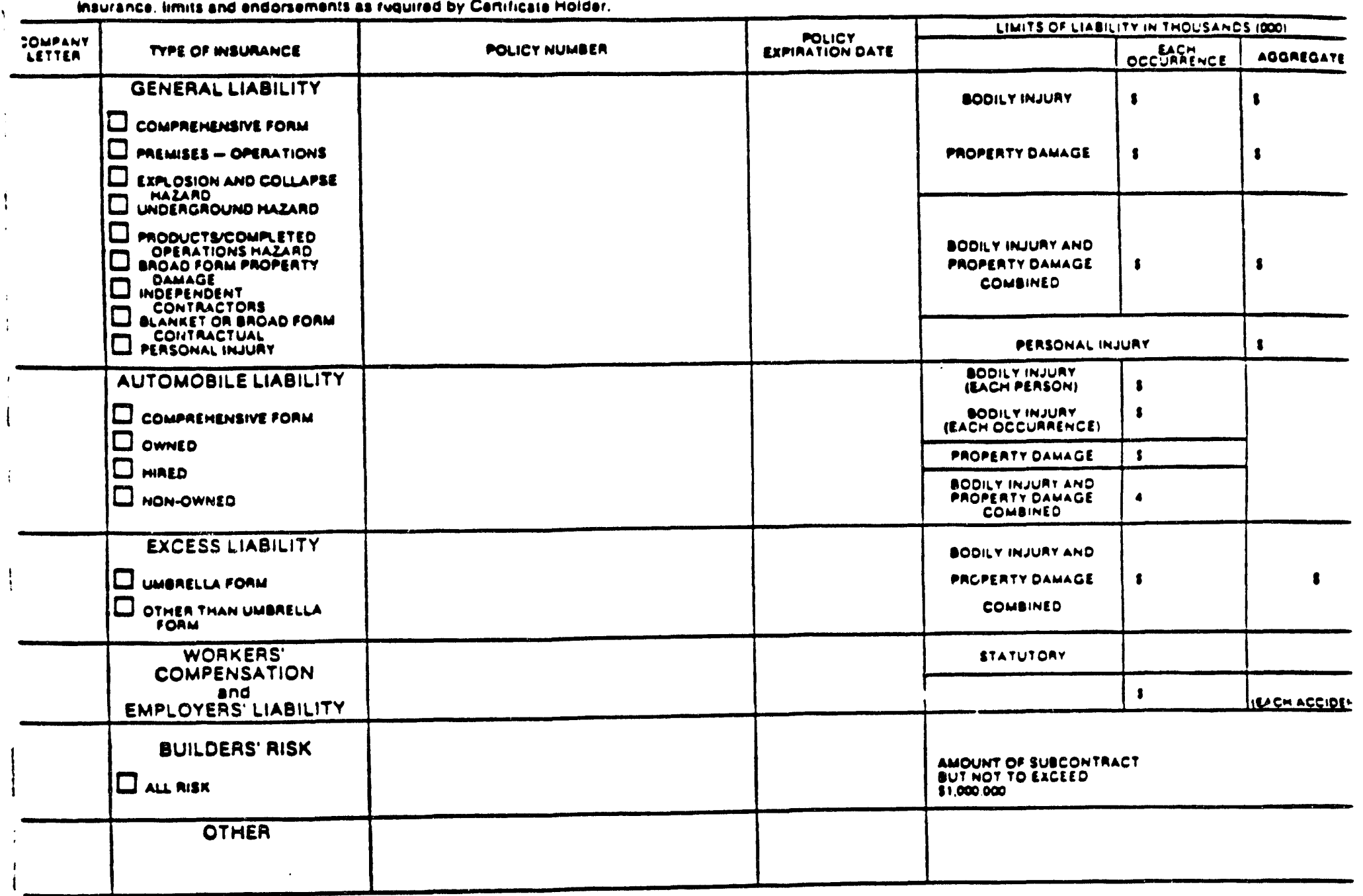

Lesued in connection with MK-Forousen Contract NO, DE-ACO4-83AL 18700 and/or Subeontractor No.

Additional insureds included: MK-FEROUSON COMPANY AND THE UNTTED STATES DEPARTMENT OF ENEROY Leeation and Deseription of oparations Insurad:

CANCELLATION: Snould any of the above described polieles be eancelled belore the expiralion date thereot. of not renewed at expisation date, the issuing company will mall 30 days advance written nolice lo the bolow named cenificalo nolder.

MAME ANO ADOAESS OF CEATIRICATE MOLOEA

MK-Ferguson Company

P.O. Box 9136

Albuguerque, NM 87119

OATE issue 0 


\section{coverage}

1. Worker's Eompensation

2. Employer's Liability

3. Comprehensive General Liability including products and completed operations

$$
\text { Bodily Injury }
$$

Property damage

or

4. Comprehensive Automobile Liabillty

$$
\text { Bodily Injury }
$$

Property Damago

or

5. All Risk Builders Risk for physical loss or damage 10 work performed under the Subcontract including materials, supplies 8 equipment on and off site If intended to become a permanent part of the work.
MINIMUM LIMITS

$$
\text { Statutory }
$$

\$ 100,000 Each Accident

\author{
$\$ 1,000,000$ Each Occurrence \\ \$500,000 Each Ciccurrenco \\ $\$ 1,000,000$ Combined Single Limit
}

\$500.000 Each Person

$\$ 1,000,000$ Each Oecurrence

\$ 500,000 Each Occurrence

$\$ 1,000,000$ Combined Single Limis

Amount of Subcontract. but not to exceed $\$ 1,000,000$.

Policies lasued for insured are endorsed as required by contract.

\begin{tabular}{|c|c|c|c|}
\hline 口 & $\square$ & 口 & $\begin{array}{l}\text { A } 30 \text { day advance written notice to Certificate Holder in the event of eancellation, non-renewal } \\
\text { or material change of the policy. }\end{array}$ \\
\hline & $\square$ & $\square$ & Certificate Holder and Principal named as Additional Insured's, as their interests appoar. \\
\hline & $\square$ & $\square$ & $\begin{array}{l}\text { Insured's insurance is primary and any insurance maintained by Certificate Hoider or } \\
\text { Principal is excess and non-contributory. }\end{array}$ \\
\hline & $\square$ & & Cross Liability or Severability of Interest Clause. \\
\hline
\end{tabular}
to include the following (mark $X$ in box if endorsement is included):

WC CGL BR 


\section{APPENDIX B}

IMPLEMENTATION PLAN FOR ACTION ITEMS

IDENTIFIED IN THE RESPONSE TO THE

ITR ON WELL DRILLING AND DEVELOPMENT 


\section{IMPLEMENTATION PLAN FOR ACTION ITEMS IDENTIFIED IN THE RESPONSE TO THE ITR ON WELL DRILLING AND DEVELOPMENT}

This appendix presents a plan for implementing action items identified by the Technical Assistance Contractor (TAC) in the responses to the independent technical review (ITR) on well drilling and development. The implementation plan groups similar or complementary action items, provides a schedule of implementation, identifies the group or people responsible for the changes, and provides an estimate of approximate hours needed to implement the changes. The four major action items are 1) ITR Reevaluation, 2) Well Installation Standard Operating Procedure (SOP) Review and Revision, 3) Well Installation Contract Review and Revision, and 4) TAC and U.S. Department of Energy (DOE) Communications Improvement. Table B1 is the estimate of hours needed to implement the plan and is for budgeting and planning purposes for the remainder of this fiscal year and the upcoming fiscal year.

Implementation of the action items represents ongoing improvements to TAC procedures, resulting in continued improvements to technical quality and lower overall project costs. 


\section{ITR REEVALUATION}

Personnel: ITR review team, personnel that implemented recommendations described in this document, TAC and DOE personnel affected by the changes.

Action Plan: Follow the same general guidelines of this initial ITR.

Estimate of Hours to Implement:

Hydrologists $\quad 80$

Contracts 20

DOE 40

ITR Review Group 300

Total 440

Task Start: June 1, 1995

Task End: August 1, 1995 


\section{WELL INSTALLATION SOP REVIEW AND REVISION}

Personnel:

Three members of the Characterization and Remedial Design (CARD) Group, one member of the Quality Assurance (QA) Group, and one member of the Health and Safety Group to review and revise the SOPs; senior review by Jim Gibb and Fletcher Driscoll.

\section{Action Plan:}

A team consisting of TAC members experienced in well installation and development will review and revise applicable SOPs. The primary reference for this effort will be ASTM Standards on Ground Water and Vadose Zone Investigations (ASTM, 1994). Where applicable, the American Society for Testing and Materials (ASTM) standards will be adopted.

The SOP review and revision team will be hydrogeologists and engineers from the CARD Group and a member of the QA Group. The facilitator will be Anchor Holm, the CARD staff manager, who will direct the effort. Issues involving contracting will be addressed by a team consisting of at least one representative of the contracts, QA, and CARD Groups. Because the changes and improvements will have the greatest technical impact on the CARD, the facilitator for both groups (the SOP review team and the contract review team) will be Anchor Holm.

In addition to an overall review, the following specific items will be addressed:

- Consistency between the QAIP and SOPs.

- Field-to-office communications.

- Well diameter.

- Well screen and sand pack selection.

- Well installation methods and materials.

- FTR selection and review process.

At a minimum, the following SOPs will be evaluated and revised, as necessary:

\section{SECTION 14}

14.1.2 Training and Instructions for Field Technical Representatives

14.1.3 The Technical Representative (TR)

14.1.4 Verification of Grout for Monitor Wells

14.1.5 FTR Daily Diary

14.1.6 Procedures for Completing the Daily Field Activity Report

14.1.7 Field/Off-Site Procurement of Supplies and Services

14.2.1 Evaluation of Drilling Firms for Geologic and Hydrologic Scopes of Work

14.3.2 Trenching Procedure for Analysis of Fault Capability

14.3.3 Borehole Geophysical Logging

14.3.4 Piezocone Testing

14.4.1 Soil and Rock Core Borehole and Test Pit Logging

14.4.2 Preparation of Logs for UMTRAP Documents 
14.5.1 Procedures for Handling and Shipping of Uncontaminated Geotechnical Samples

\section{SECTION 15}

15.1.1 Site Horizontal and Vertical Control Procedure

15.1.4 Processing Site Utility Location Investigation

15.3.1 Lithologic Modeling

\section{SECTION 16}

16.1.1 Monitor Well Installation

16.1.2 Well Development

16.1.3 Slug Testing

16.1.4 Packer (Permeability) Testing

16.1.5 Pumping Tests for Aquifers

16.1.6 Soil-Water Sampler Installation and Sample Collection (Suction Lysimeters)

16.1.7 Installation/Servicing of Tensiometers and Measurement of Soil Water Potential

16.1.17 Well Decommissioning Procedures

16.1.18 Assessment of Inherited Ground Water Wells for Use at UMTRAP Sites

16.1.19 Permitting Procedures for Installing or Decommissioning Wells

16.1.20 Well Repair Procedures

\section{SECTION 17}

17.4.1 Location ID for Test Borings, Test Pits, and Monitoring Wells

Estimate of Hours to Implement:

\begin{tabular}{lr} 
Hydrologists & 414 \\
Engineers & 207 \\
Quality Assurance & 107 \\
Health and Safety & 67 \\
Senior review & 84 \\
ITR members & 80 \\
\multicolumn{1}{c}{ Total } & 959
\end{tabular}

Task Start: July 1, 1994

Task End: $\quad$ September 30, 1994 


\section{WELL INSTALLATION CONTRACT REVIEW AND REVISION}

\section{Personnel:}

One member of the CARD Group, one member of the QA Group, one member of the Health and Safety Group, and two members of the contracting department to review and revise the well installation contracts; senior review by Jim Gibb, David Neinow, and Fletcher Driscoll.

\section{Action Plan:}

In addition to an overall review, the following specific items will be addressed:

- Amount of financial liability placed on the drilling subcontractor.

- Ability of the field technical representative (FTR) and technical representative (TR) to alter well construction during field operations.

- Length and content of the well installation requests for proposals (RFP).

- Equipment, methods, and procedures specified in the contracts and RFPs.

Estimate of Hours to Implement:

Hydrologists $\quad 66$

Quality Assurance 87

Health and Safety 46

Contractors $\quad 132$

Senior review 14

ITR members $\quad 10$

Total $\quad 334$

Task Start: July 1, 1994

Task End: $\quad$ September 30, 1994 


\section{TAC AND DOE COMMUNICATIONS IMPROVEMENT}

\section{Personnel:}

Two members of the CARD Group, one member of the QA Group, and two TAC site managers, and Larry Pinkel; senior review by Jim Gibb and Roger Nelson.

\section{Action Plan:}

A review team will be selected from the TAC with the goal of improving communications within the TAC and between the TAC and the DOE. Larry Pinkel will act as facilitator. Where applicable, modifications to the quality assurance implementation plan (DOE, 1994) and SOPs will be made. Upon completion of major communications plans, the information will be presented to the TAC and DOE.

In addition to an overall review of communication practices, the following specific items will be addressed:

- Monthly site meetings.

- Communications training.

- Written follow-up memos to all meetings.

- Cellular phone communications.

- Observational approach training seminars.

- Revisions to WITS and SPEAR and follow-up training.

- TAC and DOE communications regarding site visits.

\section{Estimate of Hours to Implement:}

Hydrologists $\quad 36$

Quality Assurance 21

Senior review $\quad 45$

Site Managers $\quad 54$

Total 156 (plus entire TAC and DOE for a 4-hour seminar)

Task Start: July 1, 1994

Task End: $\quad$ September 30, 1994 


\section{REFERENCES}

ASTM (American Society for Testing and Materials), 1994. ASTM Standards on Ground Water and Vadose Zone Investigations, second edition, sponsored by ASTM Committee D-18, Soil and Rock, Philadelphia, Pennsylvania.

DOE (U.S. Department of Energy), 1994. Quality Assurance Implementation Plan, DOE/AL/62350-72, prepared by the U.S. Department of Energy, UMTRA Project Office, Albuquerque Operations Office, Albuquerque, New Mexico. 
Table B1. Detailed estimate of hours to implement findings and recommendations identified in the ITR of well drilling and development

\begin{tabular}{rlllr}
\hline Activity & Start & End & \multicolumn{1}{c}{ Discipline } & Hours \\
\hline \multirow{2}{*}{ 1. ITR Reevaluation } & \multirow{2}{*}{ June 1, 1995} & August 1, & Hydrologists & 80 \\
& & 1995 & Contracts & 20 \\
& & & DOE & 40 \\
& & & ITR members & 300 \\
& & & Subtotal & 440
\end{tabular}

2. Well Installation SOP Review and Revision

- Team Selection

- Scoping Meeting

- Review and Revise

- Senior Review

3. Well Installation Contract Review and Revision

- Team Selection

- Scoping Meeting

- Review and Revise
July 1, 1994 Sep 30, 1994

Hydrologists 6

Engineers 3

Quality Assurance 3

Health and Safety 3

Hydrologists 8

Engineers 4

Quality Assurance 4

Health and Safety 4

Senior review 4

Hydrologists $\quad 400$

Engineers $\quad 200$

Quality Assurance $\quad 100$

Health and Safety 60

Senior review 80

ITR members $\quad 80$

Subtotal $\quad 959$

July $1,1994 \quad$ Sep 30,1994

Hydrologists 3

Quality Assurance 3

Health and Safety 3

Contracts 6

Hydrologists 3

Quality Assurance 3

Health and Safety 3

Contracts 6

Senior review 4

Hydrologists $\quad 60$

Quality Assurance 60

Health and Safety 40

Contracts $\quad 120$ 
Table B1. Detailed estimate of hours to implement findings and recommendations identified in the ITR of well drilling and development (Concluded)

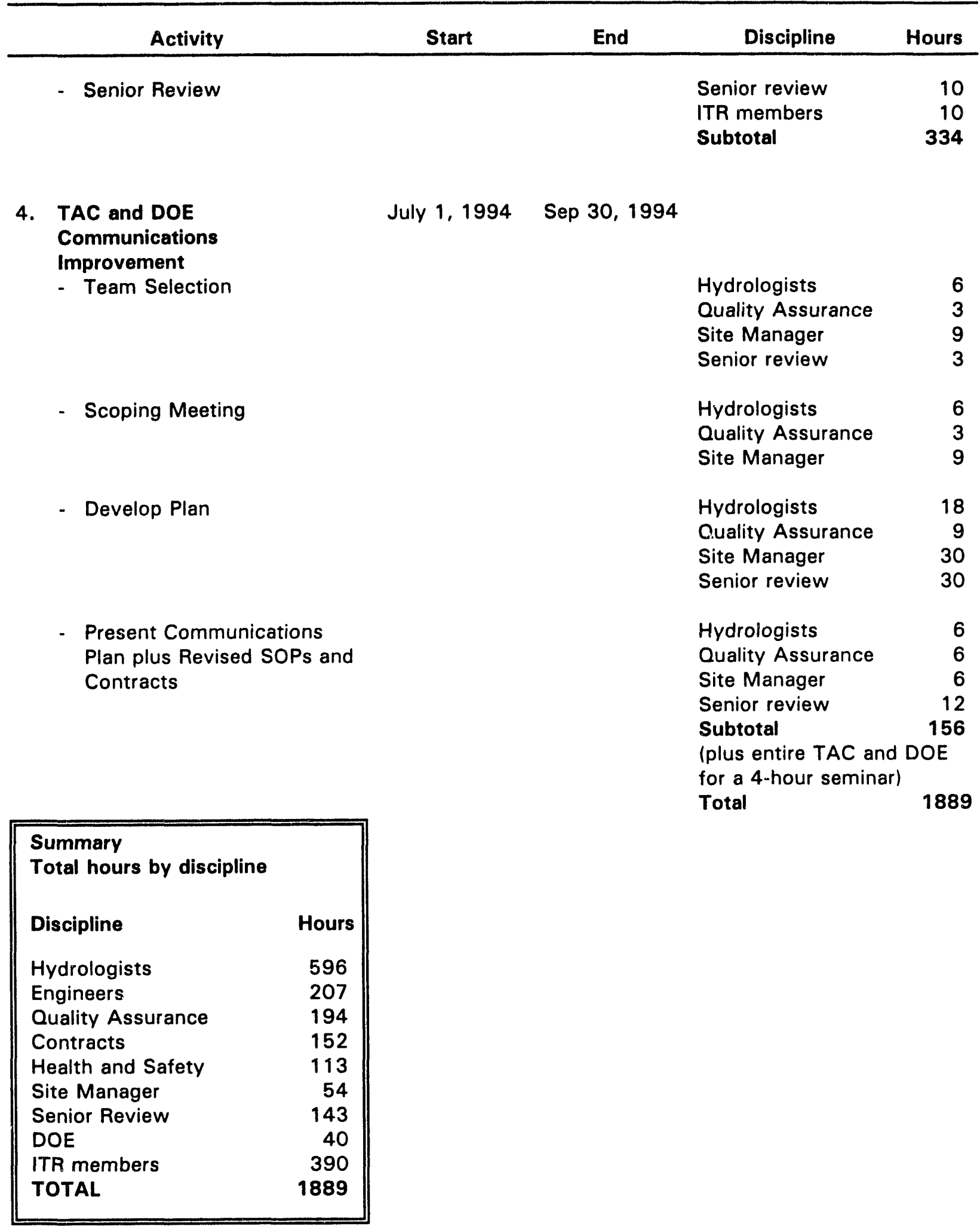



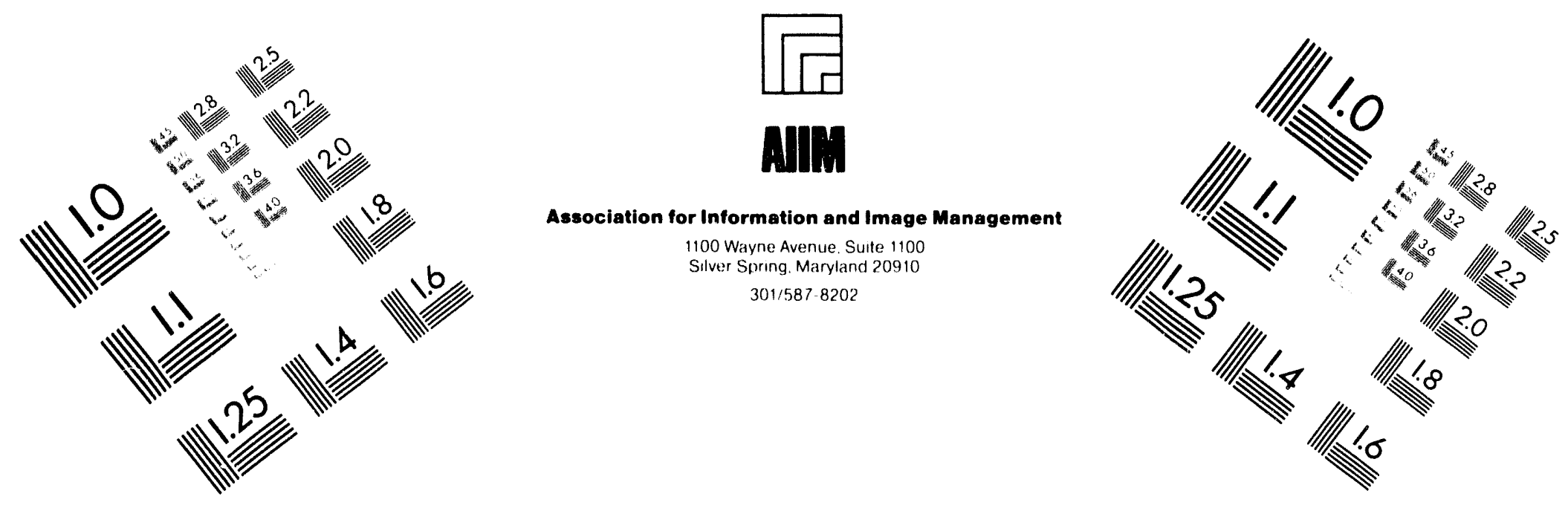

\section{Centimeter}

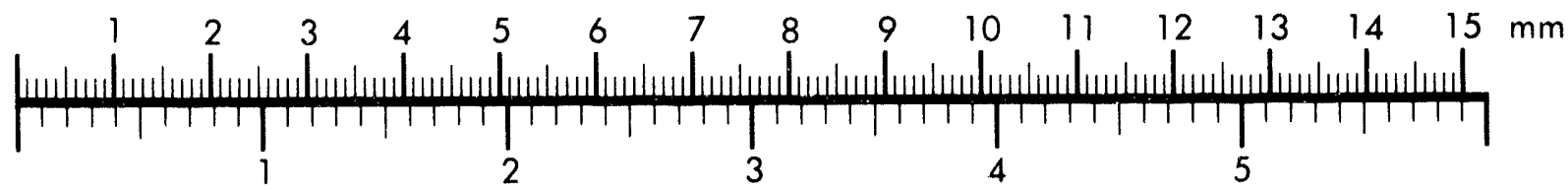

Inches
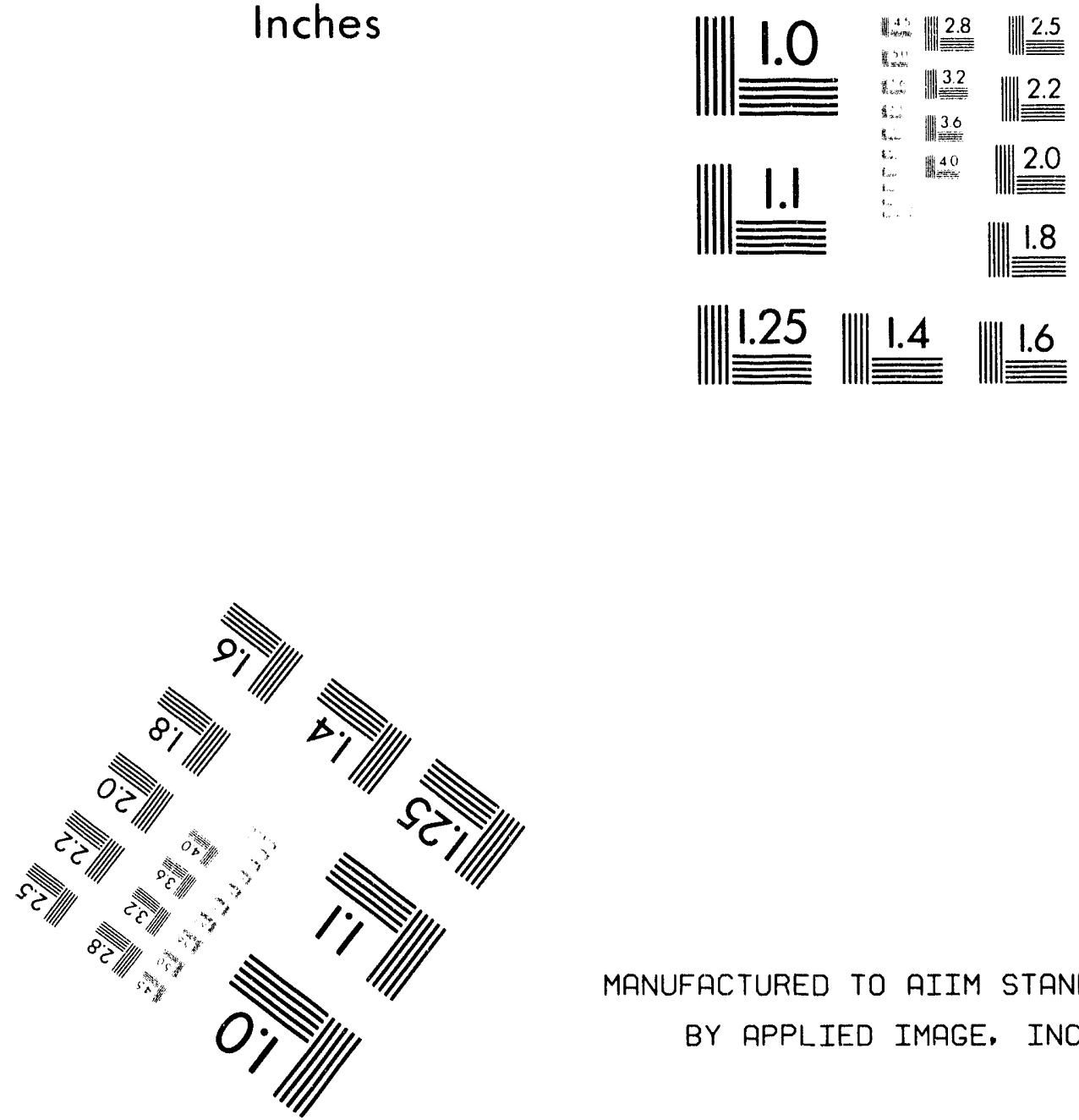

MANUFACTURED TO AIIM STANDARDS

BY APPLIED IMAGE, INC.

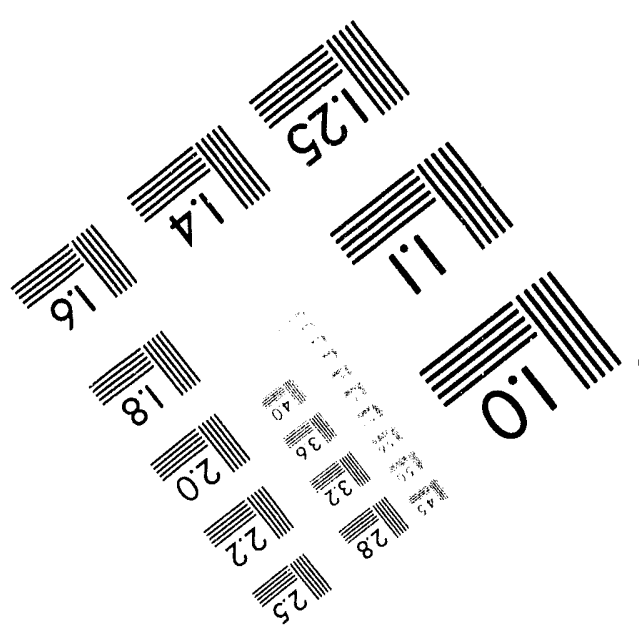




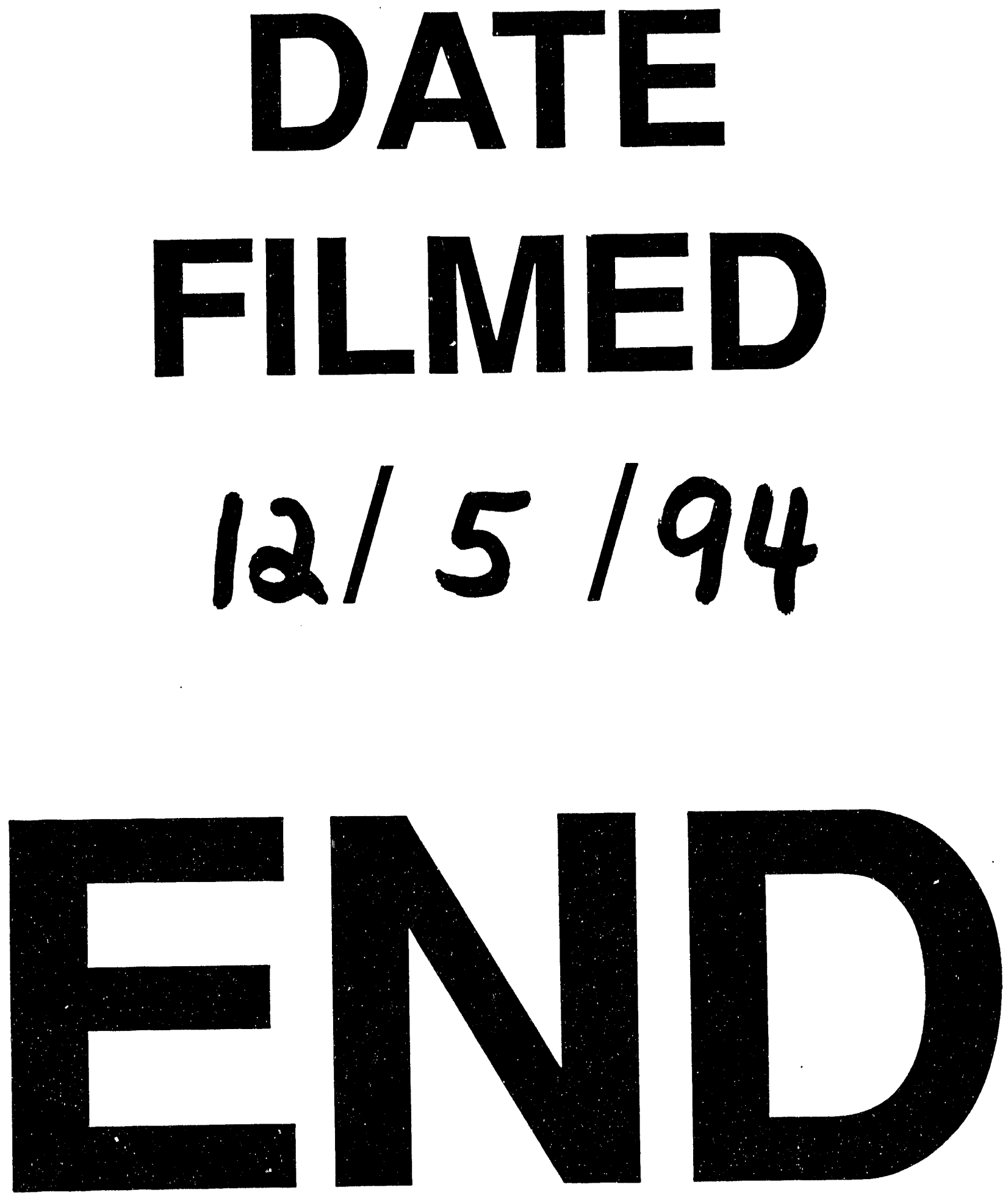